Article

\title{
Estimating the Best Exponent of the Modified Universal Soil Loss Equation and Regionalizing the Modified Universal Soil Loss Equation Under Hydro-climatic Condition of Ethiopia
}

\author{
Manaye Getu Tsige* $^{1(1)}$, Andreas Malcherek ${ }^{2}\left(\mathbb{D}\right.$ and Yilma Seleshi $^{3}(\mathbb{C})$ \\ 1 Universität der Bundeswehr München; manaye.tsige@unibw.de \\ 2 Universität der Bundeswehr München; andreas.malcherek@unibw.de \\ 3 Addis Ababa University;yilmash@yahoo.com/yilma.seleshi@aau.edu.et \\ * Manaye Getu Tsige: getumanaye100@gmail.com \\ † Adama Science and Technology University; manaye.getu@astu.edu.et
}

\begin{abstract}
Soil erosion and sediment transport are quite complex processes as they depend on physical, biological, mechanical, and chemical processes within a particular catchment. Therefore, it is highly essential to better explain engaged physical processes and means of accounting for site-specific conditions, for soil loss and sediment yield estimation. This paper mainly focuses on physical explanations behind erosion and common erosion models like Universal or Revised Universal Soil Loss Equation(USLE/RUSLE) and Modified Universal Soil Loss Equation(MUSLE). Based on the physical explanations and overall limitations, the MUSLE is selected for the application of sediment yield estimation. To regionalize the MUSLE, the main parameters of the MUSLE which directly affect the erosion process such as cover, conservation practice, soil erodibility, and topographic factors are estimated based on the past experiences from literature and comparative approaches, whereas the other parameters which do not directly affect the erosion process or which do not have physical meaning (i.e coefficient $\mathbf{a}$ and exponent $\mathbf{b}$ ) are estimated through calibration. The best exponent (b) of the Modified Universal Soil Loss Equation is 1, which results in Nash-Sutcliffe efficiency of approximately 1 . The regionalized MUSLE shows good performance for all four watersheds under our consideration and we expect the same for other watersheds of Ethiopia.
\end{abstract}

Keywords: USLE; RUSLE, MUSLE; Ethiopia

\section{Introduction}

The fate of soil erosion and sediment transport can be seen in different ways. Sediment affects the water quantity and quality in rivers, lakes, and reservoirs [115]. This is because, quantity issues of sediment dynamics concern morphological aspects along with prevailing hydraulics to affect the aquatic habitats as well as the maintenance of flood control, navigable waterways and harbors as well as coastal protection [116]. In addition, quality issues relate to nutrients and hydrophobic pollutants associated with fine sediments to influence water quality, freshwater ecosystem services, human health, and management options such as dredging or dumping sediments [116]. Soil erosion and sediment transport can have a negative impact on poverty reduction and sustainable development. For example, it results in crop yield reduction in Sub-Saharan Africa[25]. If we particularly consider Ethiopia, soil erosion and sediment transport are some of the key problems for the sustainable development of the country. For example, it results in sedimentation of water supply, irrigation, and hydroelectric power reservoir. Some of these sediment affected reservoirs are Koka hydroelectric power reservoir[22], Gilgel Gibe 1 hydroelectric power reservoir[24], Angereb water supply reservoir[23], Selamko and Shina irrigation reservoirs [28] and many more[30,31]. Furthermore, soil 
erosion leads to crop production reduction[26], lowers groundwater table [27], natural lake sedimentation $[43,47,49]$ and economic loss[26,29] in Ethiopia.

Most of the tropical countries in the Eastern, Central and Southern Africa have no appropriate and accurate soil erosion models as it was reviewed and pointed out by [120]. In Ethiopia, there is no commonly adopted soil erosion and sediment transport model; this may be because of limited hydrological and catchment data as it was reviewed and reported by $[30,33,53]$. However, soil erosion, sediment transport, deposition, consolidation and re-suspension are quite complex processes as they depend on physical, biological, mechanical and chemical processes within a particular catchment. Thus, the sedimentation processes are affected by weather and hydrological conditions, temporal and spatial distribution of rainfall, rainfall intensity, hydraulics of flow, topography, density and pattern of land cover, impact of land use change on soil erodibility [57], stream network, types and extent of soil conservation and flood protection works, temporal and spatial variation of soil physical properties,chemical properties and mineralogical constituents, biological properties and constituents, and soil mechanical properties. Some of these properties and constituents that affect soil erosion and sediment transport are soil texture [12,117], soil structure [12], particle density and volume fraction [64], pore size distribution [66], viscosity [67], bulk density [68], settling velocity [69], consistence [76], permeability [12], particle size distribution [64], soil moisture [60],gravel content [117], bed roughness [70], history of sediment bed formation and consolidation [71], cohesion [82], soil shear strength [83], compaction [65], gypsum content [54], calcium carbonate content [58], soil salinity [63], organic carbon content [55], soil hydrogen ion concentration $(\mathrm{pH})$ [59] for soil acidity and sodicity, cation exchange capacity [73], soil base saturation [74], potassium, nitrogen and phosphorus fertilizers [75], organic matter content [56], Bioturbation [72], presence of micro-organisms like microphytobenthos [77], soil microbial biomass [80], macrofaunal species [81], biofilm formation [62], biochar [61], glomalin [78], antibiotics in the soil [79], etc.

Therefore, it is highly essential to better explain engaged physical processes and means of accounting for site-specific conditions, for soil loss and sediment yield estimation. Commonly used soil erosion models are Universal Soil Loss Equation (USLE)[12], Revised Universal Soil Loss Equation(RUSLE) [20] and Modified Universal Soil Loss Equation(MUSLE). In connection to these models, similar erosion models are RUSLE1, RUSLE2(http:/ / www.ars.usda.gov/Research/docs.htm?docid=6010 and the Chinese Soil Loss Equation (CSLE) [21]. The USLE is the foundation for others; it is used to estimate annual soil loss from field area, where the extent of erosion from sheet to rill erosion. However, it does not consider gully erosion, streambank erosion, streambed erosion, mudflow, massive land movement due to landslides or slumps. In fact, the USLE is an empirical soil loss model, is given by[12] :

$A=R K L S C P$

where, where $R$ is the rainfall erosivity factor, $K$ is the soil erodibility factor, $L$ is the slope length factor, $S$ is the slope steepness factor or $L S$ is the topographic factor, $C$ is the cover factor, and $P$ is the soil conservation practice factor.

Basically, the selection of soil erosion modelling techniques and approaches are based on data requirement and availability (both quality and quantity of data), limitations of a model (basic assumptions and principles each model follows), and nature of the model (performance of the model at a specific condition). As a part of the model selection criteria, we considered physical explanation behind the above models, physical connection between factors, suitability of the models toward a specific location, and experiences of some other researchers about the important behavior of the models. Accordingly, the following limitations and advantages are drawn.

If we consider a physical explanation behind the models; the USLE/RUSLE depends on rainfall impact energy, and we expect soil detachment due to the rainfall impact. However, the rainfall impact or hammering also contributes to subsoil compaction, and it may reduce subsoil erosion. Yes, of course, we expect soil detachment due to the 
rainfall impact, however, we can not exactly tell in which direction a soil particle jumps or moves, where it reaches, or where measurement can be taken. Furthermore, the rainfall impact does not tell us how much energy is required to detach soil particles (soil strength or resistance against the rainfall impact energy). If the particle jumping due to the rainfall impact is not considered, it is a combined action of the rainfall and runoff that causes soil erosion and sediment transport from a field, therefore, it is based on this principle that the amount of soil loss from the field can be measured at bottom of a slope. This is because, in the beginning of rain, more soil erosion due to the impact of rainfall and less sediment transport is expected. At the latter time, less soil erosion due to the compaction but more sediment transport by runoff is expected. This can be a case particularly in the tropics where heavy rainfall compacts soil, infiltration decreases, runoff dominates quickly, and subsequently, more erosion in the beginning of rain is expected. As we said above the USLE/RUSLE/RUSLE2/CSLE considers the rainfall impact energy for soil detachment but it does not consider energy for sediment transport. The rainfall impact leads to a sheet to rill erosion which mainly erodes topsoil. However, runoff concentration leads to gully formation (which erodes subsoil), riverbank erosion, and bedload transport.

If we consider the physical connection between factors, as far as we are talking about the rainfall impact energy for soil detachment; the physical connection between the rainfall erosivity, soil erodibility, topographic, cover, and conservation practice factors of the USLE/RUSLE is not convincing. One evidence for this is that, for instance, the soil cover factor reduces rainfall impact energy but the soil conservation practice factor does not reduce the impact energy of the rainfall.

If we consider the suitability of the models toward specific conditions or locations, in tropical Africa, the USLE and RUSLE are difficult to apply. This may be because unrealistic values were obtained for tropical soils from the equation's erodibility nomograph (Mulengera and Payton, 1999; Ndomba, 2007) as cited in [8]. It has also been observed that the table that was developed for estimating crop and soil management factors in the USA is inconsistent with farming practices in tropical Africa (Mulengera and Payton, 1999) as cited in[8].

If we consider data requirement and availability, the USLE/RUSLE requires less than 30 minutes maximum rainfall intensity for its rainfall erosivity factor. We have daily rainfall data but we do not have $30 \mathrm{~min}$ rainfall data to test the USLE/RUSLE using its original data requirement; therefore, we can not minimize uncertainty. It is also required that temporal and spatial distribution of rainfall should be captured at different points in a large watershed. This leads us to check whether the existing gauging stations are enough or not to capture the rainfall distributions of the watersheds under our consideration. In addition to several missing climatic data, the spatial distribution and density of the gauging stations are in question for the large watersheds of Ethiopia. Practically, it is not easy to test the USLE/RUSLE/ at the large watersheds in Ethiopia. However, the USLE/RUSLE was applied at different parts of Ethiopia following similar or different approaches to estimate any of its factors (e.g, [28,33-37,39-44,46,48]).

If we consider the experiences of some other researchers, the USLE/RUSLE is widely used with a combined sediment delivery ratio (SDR) to calculate sediment yield at the outlet of watershed. It has been observed that the delivery ratios to determine the sediment yield from the USLE can be predicted accurately but varies considerably [6]. The sediment delivery ratio varies with storms; the assumption of a constant SDR adds another source of error to the estimates as it was reviewed and reported by [5]. The reason for this may be due to the variation in rainfall distribution over time, from year to year [6]. The USLE is more accurate for soils with medium texture and slopes of less than $400 \mathrm{ft}$ in length with a gradient ranging between $3 \%$ and $18 \%$, and it is managed with consistent cropping practices that are well represented in plot scale erosion studies [12]. It is also warned that the farther these limits are exceeded, the greater will be the 
probability of significant extrapolation error [12]. For further reference, other problems connected to the USLE/RUSLE are discussed in [119].

Based on the above discussions, if we depend on runoff rather than rainfall, and if we take a measurement of runoff and sediment at one point (mainly at the outlet of the large watershed), then the modelling of sediment yield can be improved. This may be also because soil erosion depends on sediment being discharged with the flow; it varies with runoff and sediment concentration [119]. Further more, while considering runoff for the sediment yield modelling, we can take into account the effect of runoff shear stress for the sediment yield modelling [118]. Therefore, we proceed to consider the MUSLE which mainly depends on runoff energy for soil detachment and sediment transport. The runoff factor of the MUSLE represents the energy used in transporting as well as in detaching sediment, which acts as the best indicator for predicting sediment yield at individual storm events as it was reviewed and reported by (eg., [3,118]). Therefore, we expect soil detachment and sediment transport.

Williams (1975) developed the MUSLE using 778 storm-runoff events collected from 18 small watersheds[11,123], with areas varying from 15 to 1500ha, slopes from 0.9 to $5.9 \%$ and slope lengths of 78.64 to $173.74 \mathrm{~m}$ (Hann et al.1994) as cited in [5]. The MUSLE is given by

$y=a(Q q)^{b} K L S C P$

where $y$ is the sediment yield in a given unit, $a$ is the coefficient and $b$ is the exponent ( $a=11.8$ and $b=0.56$ for USA, where the MUSLE was originally developed), $Q$ is the runoff volume in $\mathrm{m}^{3}, q$ is the peak runoff rate in $\mathrm{m}^{3} / \mathrm{s}$, while the rest of its factors are similar to that of the USLE as mentioned above. Basically, the MUSLE was developed for a small agricultural watershed, where the extent of erosion is from a sheet to rill erosion, but gully erosion is still not considered. To apply the MUSLE for a large watershed (for our case, Hombole Watershed is 762281ha, Mojo Watershed is 150282ha, Gumera Watershed is 127805ha and Gilgel Gibe 1 Watershed is 292809ha), the approach that was proposed is using the MUSLE in Soil and Water Assessment Tool (SWAT) environment. This may be because sediment yield can be more accurately estimated if the large watershed is divided into subwatersheds (area $<10$ square miles) to compensate for nonuniformly distributed sediment sources; the effect of watershed hydraulics and sediment particle size can be included by routing the sediment yield from subwatersheds to large watershed [11].

If we consider a specific behavior of the MUSLE, it was analyzed that the greater appropriateness of field and direct measurements of runoff on a storm-event basis for better performance of the MUSLE model output compared to use of indirect methods [5], and also the model provides appropriate estimates at watershed rather than experimental plot as it was reviewed and reported by[5]. In this connection if we consider SWAT, SWAT uses an indirect method (like Soil Conservation Service Curve Number) to generate runoff, then it uses the MUSLE to estimate soil loss from hydrologic response unit (which is similar to the plot scale), then SWAT routes sediment output in channels to the outlet of a large watershed. But, this also leads to accumulative error at the end due to uncertainty in the definition of a channel, channel depth and width in the SWAT environment.

If we consider the experiences of some other researchers, the MUSLE is unsuitable for the prediction of sediment yield for small storms[118]. However, the slight variation in hydrological response of watershed in terms of sediment yield might be changing in the antecedent hydrological conditions, the spatial and temporal distribution of rainfall, availability of eroded sediment throughout the watershed, which is not taken into account by the MUSLE as for many other lumped models[118].

If we consider the physical connection between factors of the MUSLE, as far as we are talking about runoff energy for soil detachment and sediment transport; the physical connection between runoff, soil erodibility, topographic,cover , and soil conservation practice factors is convincing but further refining the physical connection between the factors may become necessary. For instance, the cover and soil conservation factors play 
a role to break runoff energy so as to protect soil loss due to runoff. As slope length becomes larger and larger, there is a possibility that erosion from the upper part of the slope gets deposited at the lower part of the slope (for instance, if we consider the last runoff from the slope field after the end of rainfall). This is because, depending on the magnitude of the runoff and its sediment transport capacity, the runoff takes up more soil particles and gets concentrated on its way to the bottom of the slope. In other words, the energy of the runoff decreases as resistance against flow increases along the length of the slope, and its shear force decreases.

If we consider the suitability of the model toward a specific location, the MUSLE has been observed to give good results in various applications in some parts of tropical Africa (Ndomba, 2007) as cited in [8], and it has been successfully demonstrated in sub-Saharan Africa[8]. As per the experimental plot result of sheet erosion at Enerta study site in Ethiopia, the MUSLE was better to estimate soil loss from the cultivated field than the USLE [121].

Therefore, based on the above limitations and advantages, we test the MUSLE at a watershed scale rather than a plot scale (which is similar to hru), using measured flow data. In this regard, we have daily average flow records but we don't have daily peak flow records in our database. It follows that regionalizing the MUSLE under hydroclimatic conditions of Ethiopia becomes important while considering the following cases.

If we consider the simulation time step, daily sediment yield may not reflect daily watershed information such as land cover, soil erodibility, and conservation activities. The reason for this can be soil erosion, sediment transport, deposition, consolidation , and re-suspension are quite complex processes that depend on physical, biological, mechanical, and chemical activities within a large heterogeneous watershed. Due to these complex processes, the soil that was eroded at an unknown last time can be transported, deposited, consolidated, re-suspended, and reach an outlet at a different times. Therefore, measured sediment at the outlet at the current time may not reflect the current information about the watershed; but may be unknown last time. This may be because sediment that was deposited along the length and bottom of the slope by small runoff energy at a previous time, can be transported by high runoff energy at the current time. In the original development of the USLE, the annual soil erodibility factor was taken to compute the annual soil loss from the unit plot. Based on authors[12] formulation, we can conclude that annual soil erodibility is the average of soil erodibility ranging from a loose to compacted soil due to rainfall impact. As the soil erodibility factor of the USLE and MUSLE is the same, the annual time step is preferred over the daily time step (in the case of SWAT). Therefore, the annual simulation time step is selected to use the important features of the MUSLE; to take into account gully erosion (gully erosion is usually estimated on an annual basis[122]; it is important to note here is that gully erosion is a common problem in Ethiopia( eg.,[32,33,38,45,50])); to take into account overall gradual changing activities like cyclic behavior of agricultural activities, conservation practice, flood protection activities, plant growth and harvest with respect to rainfall pattern and extreme events in one-year full cycle. And also to take into account quite complex processes of soil erosion, sediment transport, deposition, consolidation, and re-suspension at different seasonal variations of weather in a one-year full cycle. In connection to the simulation time step, if we see the experience of other researchers, for example, authors[10] estimated mean annual soil loss by regionalizing the factors of the MUSLE for application to a data-scarce catchment in South Africa. The combination of MUSLE with other runoff models was tested on 26 watersheds in Texas with areas from 0.7 to $513 \mathrm{~km}^{2}$; these tests showed that sediment-runoff model was feasible for predicting monthly and annual sediment yield[123].

If we consider the hydrologic response unit (hru) in the SWAT environment, as the number of hru become larger and larger, we better take into account spatial variability of land use, soil, and slope all over the watershed. To test the MUSLE at a watershed scale, 
sediment or flow routing in stream channels of SWAT is not considered (it is important to note here is that there is uncertainty in the definition of a channel, channel width, and depth in the SWAT environment). Therefore, we only considered hrus to calculate the areal weighted average to capture the spatial variation of soil, cover, conservation practice and topography.

If we consider calibration parameters, all parameters $(a, b, Q, q, K, L, S, C, P)$ of the MUSLE can potentially be used for calibration and validation[3]. In SWAT, K and $\mathbf{P}$ are calibration parameters. Authors[51] conducted global sensitivity analysis (Monte Carlo sampling) of the parameters of the MUSLE by using the extended Fourier amplitude sensitivity test (EFAST) method. Accordingly, the exponent $b$ is the most sensitive parameter to predict the amount of soil loss, followed by $\mathbf{P}, \mathbf{a}, \mathbf{L S}, \mathbf{C}$ and $\mathbf{q}$, and $\mathbf{k}^{\prime} \mathbf{s}$ influencing variables such as organic matter, soil structure class, and soil permeability class. In addition, authors[52] used Sobol's sensitivity analysis, and found that the location parameters $\mathbf{a}$ and $\mathbf{b}$ are the most sensitive parameters of the MUSLE model contributing about $66 \%$ of the variability in the output sediment yield, at upper Malewa catchment in Kenya. On storm event basis, authors[8] estimated the location parameters ( $a=12.4$ and $b=0.51$ ) of the MUSLE for Ofuloko watershed in Nigeria. In some studies, only the exponent of the model was calibrated, which is logically more acceptable as it was reviewed and reported by [5]. However, the exponent of the model does not tell us site-specific conditions like soil erodibility changes. Moreover, calibrated sediment doe not reflect actual soil erodibility and conservation practice factors on the ground unless otherwise they are measured. To accept our calibration, we should also check the calibrated value of soil erodibility and conservation practice factors against the actual ones on the ground. This is because their product effect is reflected in the MUSLE rather than their individual effect during the calibration of sediment yield. Unless otherwise, we can not reach a certain conclusion that how these factors are really affecting the soil erosion process. Therefore, the main parameters of the MUSLE which directly affect the erosion process such as cover, conservation practice, soil erodibility, and topographic factors are estimated based on the past experiences from literature and comparative approaches, whereas the other parameters which do not directly affect the soil erosion process or which has no any physical meaning (i.e coefficient $\mathbf{a}$ and exponent $\mathbf{b}$ ) are estimated through calibration. At the yearly simulation time step, the coefficient $\mathbf{a}$ is assumed to be account for site-specific conditions of a given watershed such as gully erosion, streambank erosion, streambed erosion, mudflows, massive land movement due to landslide or slumps, and sedimentation at floodplain where the original MUSLE does not account them. It also accounts for site-specific conditions such as density and pattern of land cover, nature and extent of soil conservation and flood protection work, temporal variation of soil properties, and unspecified runoff direction on slope field, which mainly affect the soil erosion control or conservation practice factor.

While taking into account the above discussions, we selected four watersheds in three different river basins to regionalize the MUSLE using topographic, soil, land use, and flow data under the hydro-climatic condition of Ethiopia, where the area of the watersheds ranges from small to large, of course in comparative speaking. The MUSLE shows good performance for all watersheds under our consideration, we expect the same for other watersheds of Ethiopia. The best exponent (b) of the Modified Universal Soil Loss Equation is 1, which results in Nash-Sutcliffe efficiency of approximately 1.

\section{Materials and Methods}

\subsection{Description of Study Areas}

To begin our work, we considered four watersheds such as Gumera watershed in Abbay River Basin, Gilgel Gibe 1 watershed (at Assendabo) in Omo-Gibe River Basin, and Hombole and Mojo watersheds in Upper Awash River Basin, in Ethiopia. We describe the topography, hydro-climate, land use, and soil of the study areas based on the data which were prepared or obtained from different sources. Therefore, our description 
of the study area is based on the digital elevation models which were downloaded from the US Geological Survey; climatic data which were obtained from the National Meteorology Agency of Ethiopia; flow and sediment data which were obtained from the River Basin Authority of Ethiopia; soil and land use maps which were prepared from different sources by comparative and logical approaches. To identify the boundary of the river basin or watershed, streams are generated by delineating digital elevation model in SWATplus-QGIS plugin, and then the streams' shapefile is exported to the Google Earth Pro as keyhole markup language to identify an outlet point of the watershed, and then the watershed is delineated by using its outlet point, and its shapefile is exported to the Google Earth Pro as keyhole markup language to identify its geographic boundary(it is important to note that delineated watershed should lie inside the streams that were generated at the previous step).

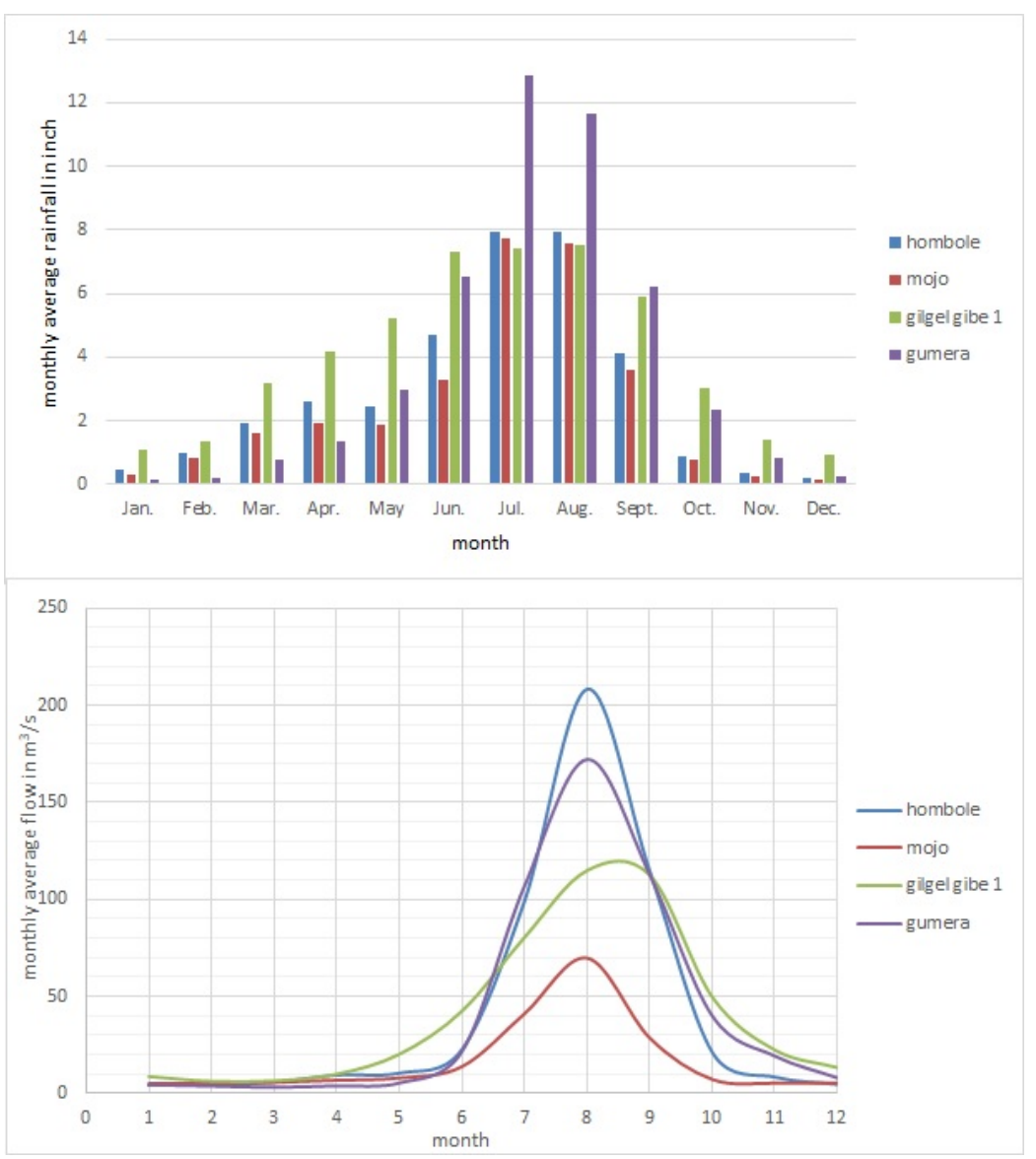

Figure 1. Monthly average rainfall, and monthly average outflow discharge at the main outlet point of each watershed under our consideration.

\subsubsection{Upper Awash River Basin}

Upper Awash River Basin drains into Koka hydroelectric power reservoir. Its geographic boundary lies between latitude $8.1036^{\circ} \mathrm{N}-9.305^{\circ} \mathrm{N}$ and longitude $37.950^{\circ} \mathrm{E}-$ $39.295^{\circ} \mathrm{E}$, and its main outlet point lies at latitude $8.468521^{\circ} \mathrm{N}$ and longitude $39.156143^{\circ} \mathrm{E}$. The basin comprises two main gauged watersheds: Hombole and Mojo watersheds which cover $65.26 \%$ and $12.87 \%$ of the total area of the basin respectively, and the basin also includes an ungauged watershed which covers $21.87 \%$ of the total area of the basin. The total drainage area of the basin is estimated to be $11680.25 \mathrm{~km}^{2}$. 


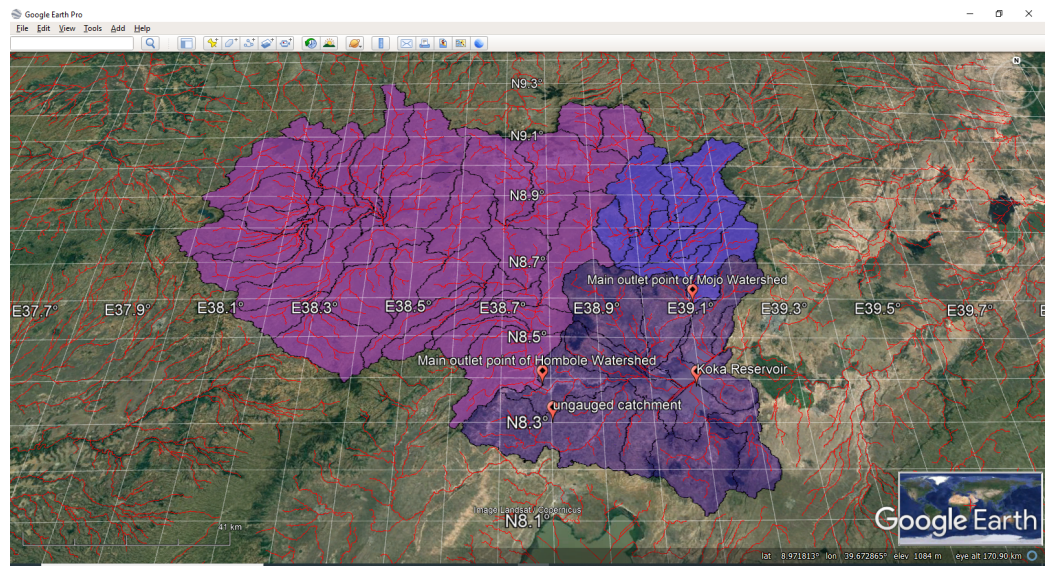

Figure 2. Hombole and Mojo watersheds in Upper Awash River Basin.

In the basin, there are active socio-economic activities like agricultural, industrial, and commercial activities. On the other angle, the basin experiences catastrophic flooding, and land degradation problems due to severe gully erosion. The gully erosion assessment in the basin was reported by[50]. Just to report average and extreme events in the basin based on the available records (it is important to note that missing records are not considered), the maximum daily rainfall was recorded over twenty-seven gauging stations within the record time period from 1986-2020 is 198.40 inches, and the average of the records is 2.82 inches. The list of these stations is given in the appendix A.1. The daily maximum and minimum temperatures were recorded over thirteen stations within the record time period from $1986-2020$ are $43.40^{\circ} \mathrm{C}$ and $-8.40^{\circ} \mathrm{C}$, and the average of the maximum and minimum temperature records are $26.54^{\circ} \mathrm{C}$ and $10.90^{\circ} \mathrm{C}$ respectively. The list of these stations is given in the appendix A.1. The maximum and minimum relative humidity were recorded at either of the Addis Ababa (lat. $9.01891^{\circ} \mathrm{N}$ and $\log .38 .7475^{\circ} \mathrm{E}$ ) or Debre Zeit stations (lat. $8.733333^{\circ} \mathrm{N}$ and $\log .38 .95^{\circ} \mathrm{E}$ ) within the record time period from $1986-2012$ are $100 \%$ and $1 \%$ respectively, and the average of the records is $58.23 \%$. The maximum wind speed and the maximum sun hours duration were recorded at the Debre Zeit(AF) station within the record time period from 1994-2005 and 1994-2013 are $8.30 \mathrm{~m} / \mathrm{s}$ and $12.60 \mathrm{hrs}$, and the average of the wind speed and sun hours duration records are $1.40 \mathrm{~m} / \mathrm{s}$ and $7.98 \mathrm{hrs}$ respectively.

For the Hombole watershed, the average, maximum and minimum elevations are $2353.78 \mathrm{~m}, 3565 \mathrm{~m}$, and $1698.94 \mathrm{~m}$ above sea level respectively. The daily maximum and minimum outflow discharge were recorded at the main outlet of the watershed within the record time period from $1990-2016$ are $803.10 \mathrm{~m}^{3} / \mathrm{s}$ and $0.402 \mathrm{~m}^{3} / \mathrm{s}$ respectively, and the average of the records is $43.20 \mathrm{~m}^{3} / \mathrm{s}$ provided that the missing records are not considered. Monthly average rainfall, and monthly average outflow discharge at the main outlet point of the watershed are given in the figure 1 (it is to note that rainfall stations that lie inside and near the watershed, and those stations which have the record length from 15 to 35 years are considered to calculate a simple arithmetic average for the sake of comparison purpose). The maximum and minimum suspended sediment concentrations were recorded at the main outlet of the watershed within the record time period from 1989 to 2015 are $18.530 \mathrm{~kg} / \mathrm{m}^{3}$ and $0.136 \mathrm{~kg} / \mathrm{m}^{3}$ respectively, and the average of the records is $1.5 \mathrm{~kg} / \mathrm{m}^{3}$ provided that only available records are considered. The dominant soil types are Eutric Vertisols and Haplic Nitisols which cover $57.30 \%$ and $17.77 \%$ of the total area of the watershed respectively. Land-use changes were observed in the watershed at four time periods, the dominant land use class is agricultural land; it covers $85.70 \%$ of the total watershed area in the time period from 1989 to $2000,88.25 \%$ in the time period from 2001 to $2008,86.52 \%$ in the time period from 2009 to 2012 and $86.26 \%$ in the time period from 2013 to 2015.

For the Mojo watershed, the average, maximum and minimum elevations are $2140.4 \mathrm{~m}, 2932 \mathrm{~m}$, and $1739.86 \mathrm{~m}$ above sea level respectively. The daily maximum and 
minimum outflow discharge were recorded at the main outlet of the watershed within the record time period from $1990-2016$ are $511.189 \mathrm{~m}^{3} / \mathrm{s}$ and $0 \mathrm{~m}^{3} / \mathrm{s}$ respectively, and the average of the records is $17.21 \mathrm{~m}^{3} / \mathrm{s}$ provided that the missing records are not considered. Monthly average rainfall, and monthly average outflow discharge at the main point of the watershed are given in the figure 1 (it is to note that rainfall stations that lie inside the watershed, and those stations which have the record length from 15 to 35 years are considered to calculate the simple arithmetic average). The maximum and minimum suspended sediment concentrations were recorded at the main outlet point within the record time period from 1989 to 2015 are $37.66 \mathrm{~kg} / \mathrm{m}^{3}$ and $0.16 \mathrm{~kg} / \mathrm{m}^{3}$ respectively provided that only available records are considered. The dominant soil types are Vertic Cambisols and Eutric Vertisols which cover $46.80 \%$ and $45.06 \%$ of the total area of the watershed respectively. Land-use changes were observed in the watershed at four time periods; the dominant land use class is agricultural land; it covers $95.18 \%$ of the total watershed area in the time period from 1989 to $2000,95.39 \%$ in the time period from 2001 to $2008,93.85 \%$ in the time period from 2009 to 2012 and $93.82 \%$ in the time period from 2013 to 2015.

\subsubsection{Gumera Watershed}

Gumera watershed drains into Lake Tana. Its geographic boundary lies between latitude $11.574^{\circ} \mathrm{N}-11.9052^{\circ} \mathrm{N}$ and longitude $37.6308^{\circ} \mathrm{E}-38.1852^{\circ} \mathrm{E}$, and its main outlet point lies at latitude $11.83^{\circ} \mathrm{N}$ and longitude $37.6299^{\circ} \mathrm{E}$. The total drainage area of the watershed is estimated to be $1278.05 \mathrm{~km}^{2}$. The average, maximum and minimum elevations are $2260.45 \mathrm{~m}, 3654.33 \mathrm{~m}$, and $1795.93 \mathrm{~m}$ above sea level respectively.

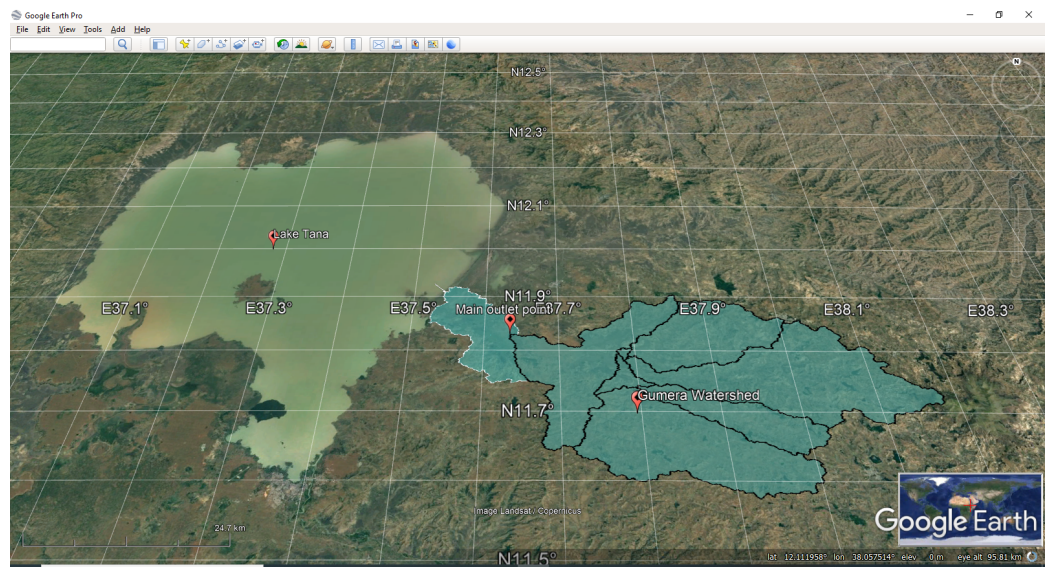

Figure 3. Gumera watershed in Abbay River Basin.

Just to report average and extreme events in the watershed based on available records (it is important to note that missing records are not considered), the maximum daily rainfall was recorded over seven gauging stations within the record time period from $1986-2020$ is 147.1 inches, and the average of the records is 3.95 inches. These stations are listed in the appendix A.1. The daily maximum and minimum temperatures were recorded over five stations within the record time period from 1986-2019 are $39.7^{\circ} \mathrm{C}$ and $-6.3^{\circ} \mathrm{C}$, and the average of the maximum and minimum temperature records are $25.38^{\circ} \mathrm{C}$ and $10.02^{\circ} \mathrm{C}$ respectively. These stations are listed in the appendix A.1. The maximum and minimum relative humidity were recorded at Debre Tabor station (lat. $11.8666^{\circ} \mathrm{N}$ and $\log .37 .9954^{\circ} \mathrm{E}$ ) within the record time period from 1988 to 2019 are $100 \%$ and $4 \%$ respectively, and the average of the records is $64.19 \%$. The maximum wind speed and the maximum sun hours duration were recorded at the Debre Tabor station within the record time period from $1988-2018$ and $1993-2019$ are $18.3 \mathrm{~m} / \mathrm{s}$ and $11.7 \mathrm{hrs}$, and the average of the wind speed and sun hours records are $1.1 \mathrm{~m} / \mathrm{s}$ and $7.01 \mathrm{hrs}$ respectively. The daily maximum and minimum outflow discharge were recorded at the main outlet of the watershed within the record time period from $2000-2017$ are $307.937 \mathrm{~m}^{3} / \mathrm{s}$ and 
$0 \mathrm{~m}^{3} / \mathrm{s}$ respectively, and the average of the records is $44.97 \mathrm{~m}^{3} / \mathrm{s}$. The maximum and minimum suspended sediment concentrations were recorded within the record time period from $1990-2017$ are $10.07 \mathrm{~kg} / \mathrm{m}^{3}$ and $0.17 \mathrm{~kg} / \mathrm{m}^{3}$ respectively, and the average of the records is $3.43 \mathrm{~kg} / \mathrm{m}^{3}$. Monthly average rainfall, and monthly average outflow discharge at the main outlet point of the watershed are given in the figure 1 (it is to note that rainfall stations that lie inside and near the watershed, and those stations which have the record length from 15 to 35 years are considered to calculate a simple arithmetic average). The dominant soil type is Haplic Luvisols which covers $69.50 \%$ of the total area of the watershed. Land-use changes were observed in the watershed at two time periods, the dominant land use class is agricultural land; it covers $84.33 \%$ of the total watershed area in the time period from 1989 to 2009 and $88.34 \%$ in the time period from 2010 to 2015.

\subsubsection{Gilgel Gibe 1 Watershed}

Gilgel Gibe 1 watershed drains into Gilgel Gibe 1 hydroelectric power reservoir. Its geographic boundary lies between latitude $7.3332^{\circ} \mathrm{N}-7.995^{\circ} \mathrm{N}$ and longitude $36.515^{\circ} \mathrm{E}$ $-37.215^{\circ} \mathrm{E}$, and its main outlet point lies at latitude $7.75^{\circ} \mathrm{N}$ and longitude $37.18299^{\circ} \mathrm{E}$. The total drainage area of the watershed is estimated to be $2928.09 \mathrm{~km}^{2}$. The average, maximum and minimum elevations are $1972.5 \mathrm{~m}, 3141.14 \mathrm{~m}$, and $80.4 \mathrm{~m}$ above sea level respectively.

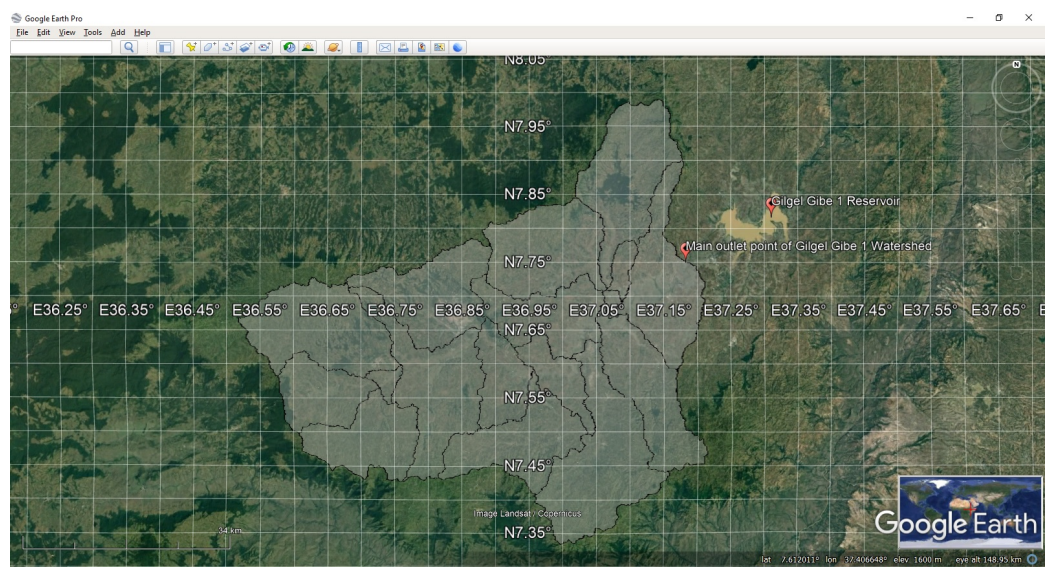

Figure 4. Gilgel Gibe 1 watershed in Omo-Gibe River Basin.

Just to report average and extreme records in the watershed based on available records (it is to note that missing records are not considered), the maximum daily rainfall was recorded over nine gauging stations within the record time period from 1986 - 2020 is 248.7 inches, and the average of the records is 4.37 inches. These nine gauging stations are listed in the appendix A.1. The daily minimum temperature was recorded over five stations within the record time period from $1986-2020$ is $0^{\circ} \mathrm{C}$, and the average of the maximum and minimum temperature records are $26.1^{\circ} \mathrm{C}$ and $12.47^{\circ} \mathrm{C}$ respectively. These five gauging stations are listed in the appendix A.1. The daily maximum and minimum outflow discharge were recorded at the main outlet of the watershed within the record time period from $2000-2015$ are $269.54 \mathrm{~m}^{3} / \mathrm{s}$ and $1.67 \mathrm{~m}^{3} 3 / \mathrm{s}$ respectively, and the average of the records is $40.97 \mathrm{~m}^{3} / \mathrm{s}$. The maximum and minimum suspended sediment concentrations were recorded within the record time period from $1990-2017$ are $0.90 \mathrm{~kg} / \mathrm{m}^{3}$ and $0.12 \mathrm{~kg} / \mathrm{m}^{3}$ respectively, and the average of the records is $0.43 \mathrm{~kg} / \mathrm{m}^{3}$. Monthly average rainfall, and monthly average outflow discharge at the main outlet point of the watershed are given in the figure 1 (it is to note that rainfall stations that lie inside and near the watershed, and those stations which have the record length from 15 to 34 years are considered to calculate a simple arithmetic average). The dominant soil types are Humic Nitisols and Mollic Fluvisols which cover 52.86\% and 25\% of the total area of the watershed. Land-use changes were observed in the watershed at two time 
periods; the dominant land use class is agricultural land; it covers $90.23 \%$ and $91.953 \%$ of the total watershed area in the time period from 1989 - 2009 and 2010 - 2015 respectively.

\subsection{Preparation of soil maps}

Soil data is required to estimate the soil erodibility factor of the MUSLE. The necessities of preparing soil maps are to assign a specific type of soil from a general category of the soil, and to maintain spatial variability of the soil. For all our watersheds, national soil maps of Ethiopia which we obtained currently from the River Basin Authority of Ethiopia show us the general category of soil. To assign a specific type of soil, we locate the shapefile of each watershed on harmonized world soil data map; we clip harmonized world soil data map to the size of our watersheds in the QGIS environment. Then, we compare national soil maps of Ethiopia, harmonized world soil map, and field observation report from the International Soil Reference and Information Centre on QGIS. Particularity for the Upper Awash River Basin, we have two soil maps which were prepared at different times, from the River Basin Authority of Ethiopia. Based on these two soil maps, we maintain spatial variability of the soil just after the specific type of soil was assigned. We locate areal coverage of the specific type of soil on the old map, that completely lies inside on the large area of another specific type of soil on the current soil map. Then, we clip the specific type of soil on the current map to the size of the specific type of soil on the old map just to make a hole on the current soil map. Then, to obtain the final map, we add the specific type of soil on the old map to fill the hole of the current map. Therefore, soil maps of each watershed, which are finally prepared are given in the figures5, 6 and 7.

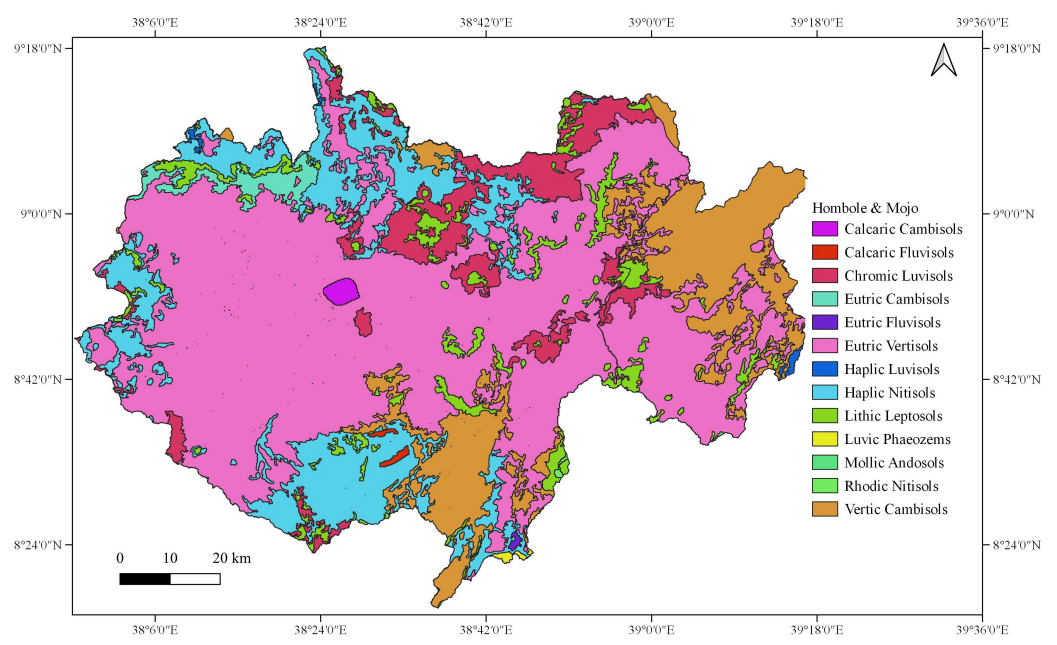

Figure 5. Soil maps of Hombole and Mojo Watersheds. 


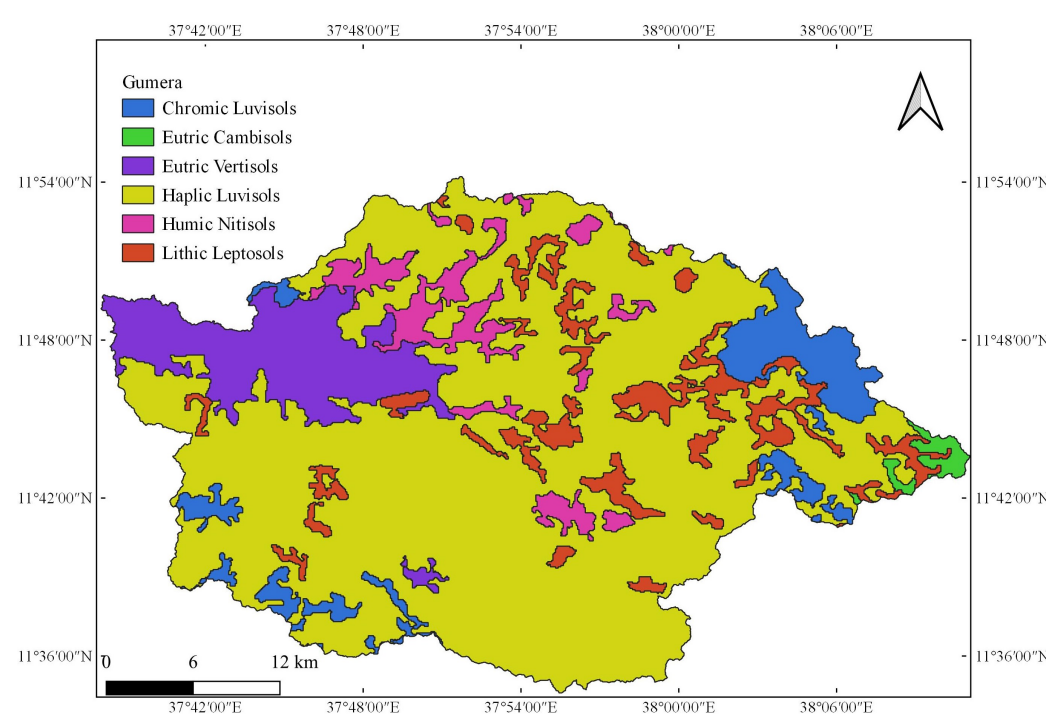

Figure 6. Soil map of Gumera Watershed .

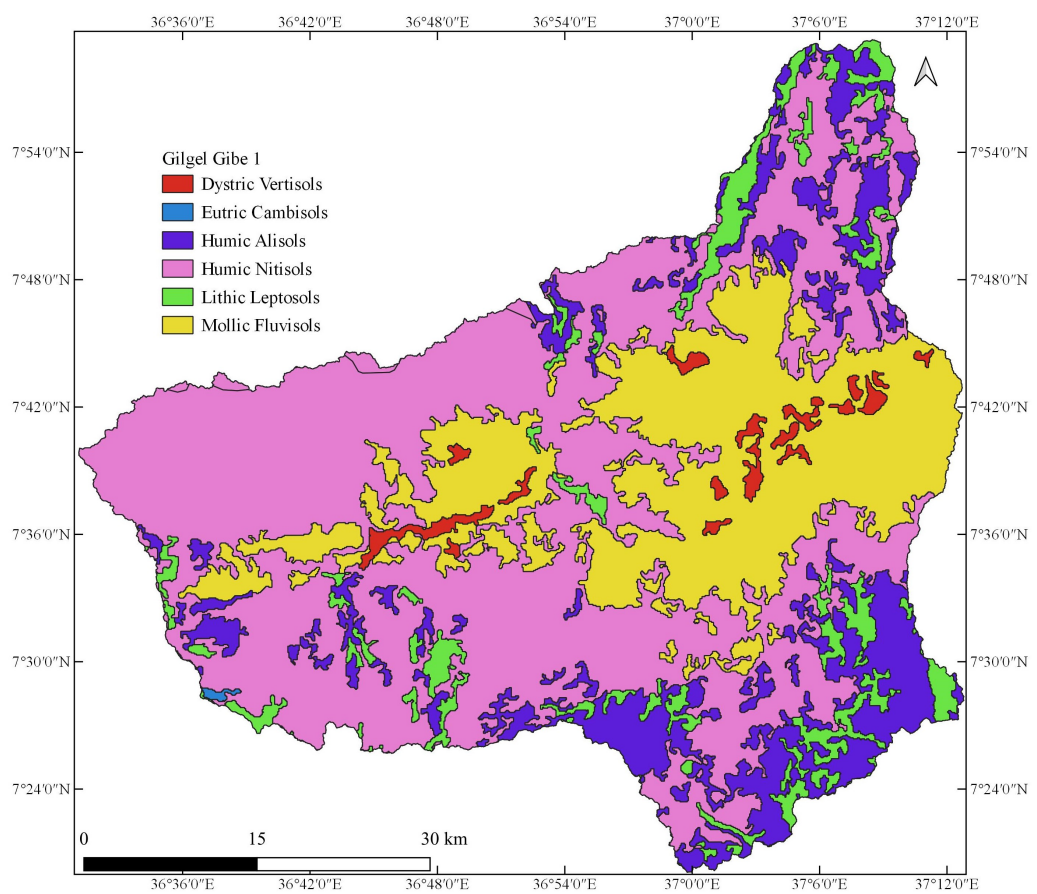

Figure 7. Soil map of Gilgel Gibe 1 watershed.

\subsection{Preparation of land use maps}

Preparation of land use data is necessary to estimate soil cover and conservation practice factors of the MUSLE. Based on our assessment of land use and land cover by the support of Google Earth Pro, Planet Explorer, literature review (eg.,[84-87], and land use maps from the River Basin Authority of Ethiopia, land-use change has been observed in the study areas. As the basis of the classification of land use maps, dominant land use classes are categorized at $30 \mathrm{~m}$ spatial resolution. This is the acceptable level of spatial dimension to consider spatial variability of land use at a tolerable level of accuracy. As a result, land use maps of each watershed are prepared based on a comparative approach and logical sequence. To prepare land use maps by the comparative approach, sample geographic coordinate points with its defined land use classes are collected from the Global land service map; the Normalized Difference Vegetation Index (NDVI) is prepared from the Landsat images to identify vegetation and bare land; easily observable 
urban, forest and agricultural land on historical imaginary in the Google Earth Pro at different acquisition dates are digitized. A time demarcation of the land-use change classification depends on a number of available baseline land use maps per watershed; the time boundary of the Global land service maps, and acquisition dates of cloud-free Landsat satellite images and historical imaginary in the Google Earth Pro. As a result, the time demarcation of land-use change for Hombole and Mojo watersheds are 1989 - 2000, 2001 - 2008, 2009 - 2012, 2013 - 2015, whereas for Gumera and Gilgel Gibe 1 watersheds are $1989-2009$ and $2010-2015$.

During the comparison of the above land use data files with the baseline national land use maps of Ethiopia on QGIS and Google Earth Pro; the vector data files are converted from the shapefile to the keyhole Markup Language(KML) and vice versa. To prepare a land use map by the logical sequence, we check whether a change in land-use from one class to another is possible or not (for example, is the change from urban to agriculture possible?) as far as we are doing like comparison of different land use data files, which were prepared or acquired from different sources at the specified time demarcation. Particularly for the Upper Awash River Basin, land use classes which find on the previous baseline map but not on the latter map, are included on the latter map based on the logical sequence, and vice versa. And also missing land use classes like water bodies are added on either of the maps during the comparison of the maps with other sources like historical imaginary in the Google Earth Pro. While following these procedures, the land use maps which are finally prepared for each watershed are given in the figures $8,9,10,11,12,13,14$ and 15

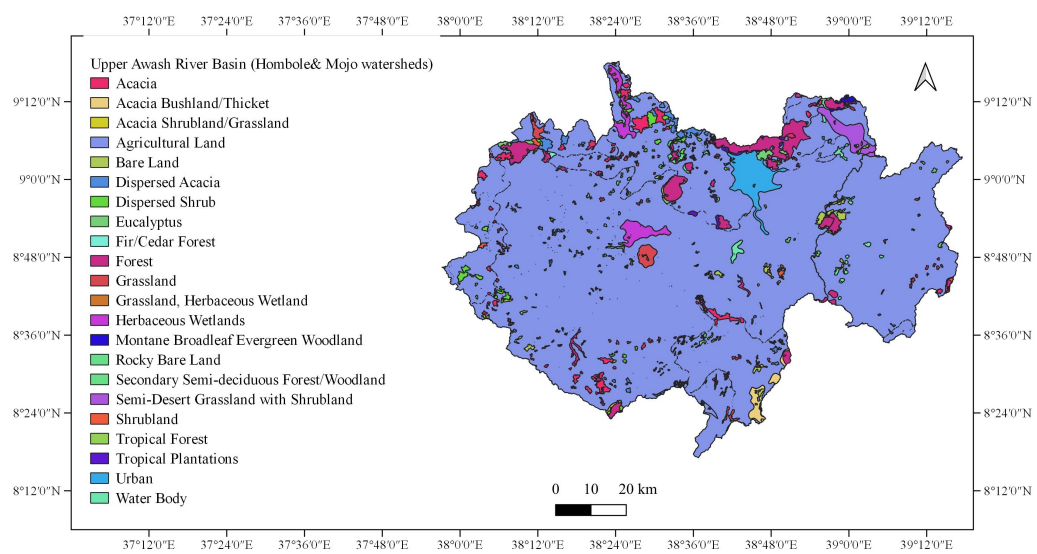

Figure 8. Land use map of Upper Awash River Basin (Hombole and Mojo Watersheds) from 1989 to 2000 .

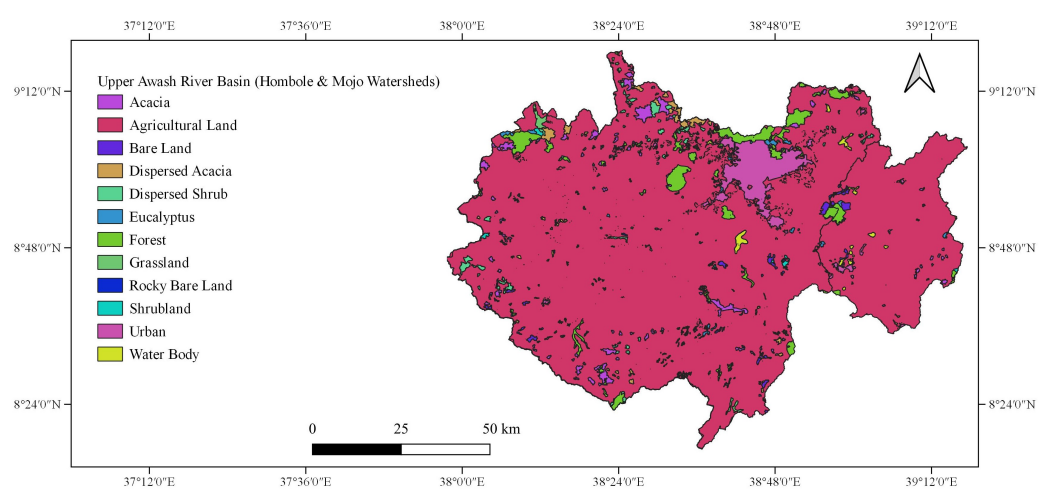

Figure 9. Land use map of Upper Awash River Basin (Hombole and Mojo Watersheds) from 2001 to 2008 . 


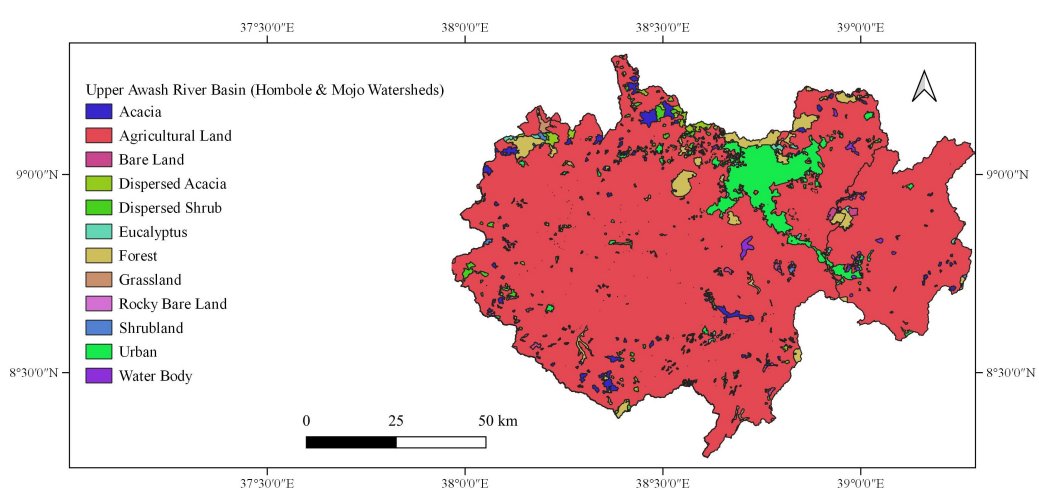

Figure 10. Land use map of Upper Awash River Basin (Hombole and Mojo Watersheds) from 2009 to 2012.

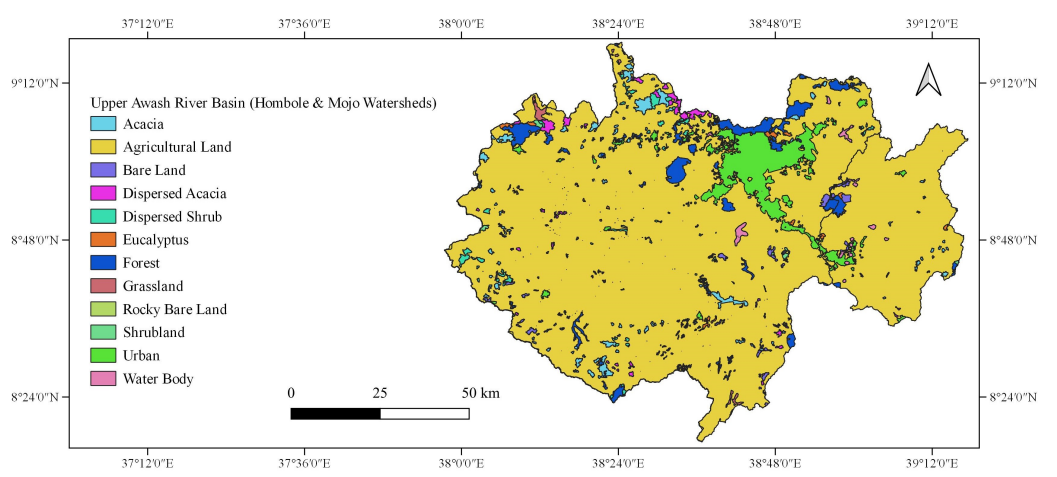

Figure 11. Land use map of Upper Awash River Basin (Hombole and Mojo Watersheds) from 2013 to 2015 .

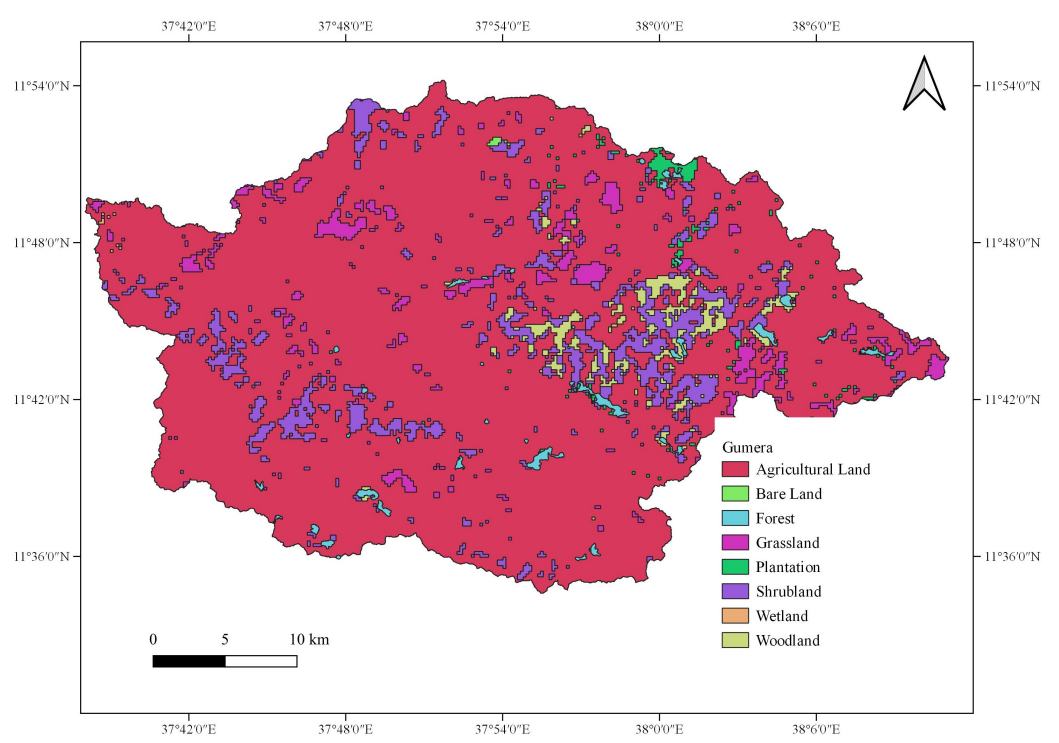

Figure 12. Land use map of Gumera Watershed from 1989 to 2009. 


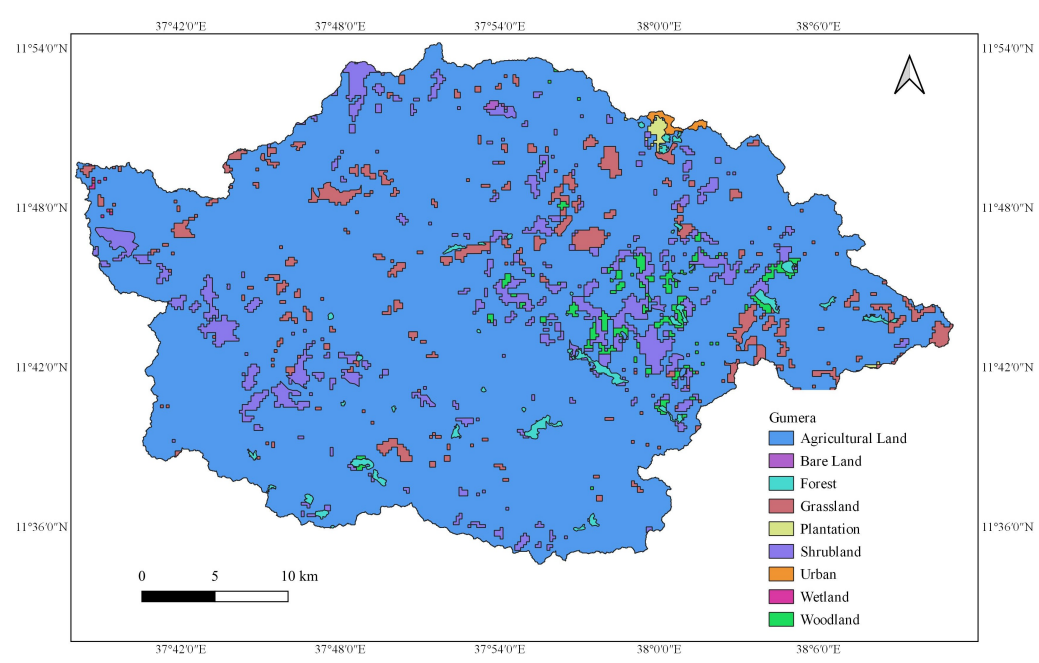

Figure 13. Land use map of Gumera Watershed from 2010 to 2015.

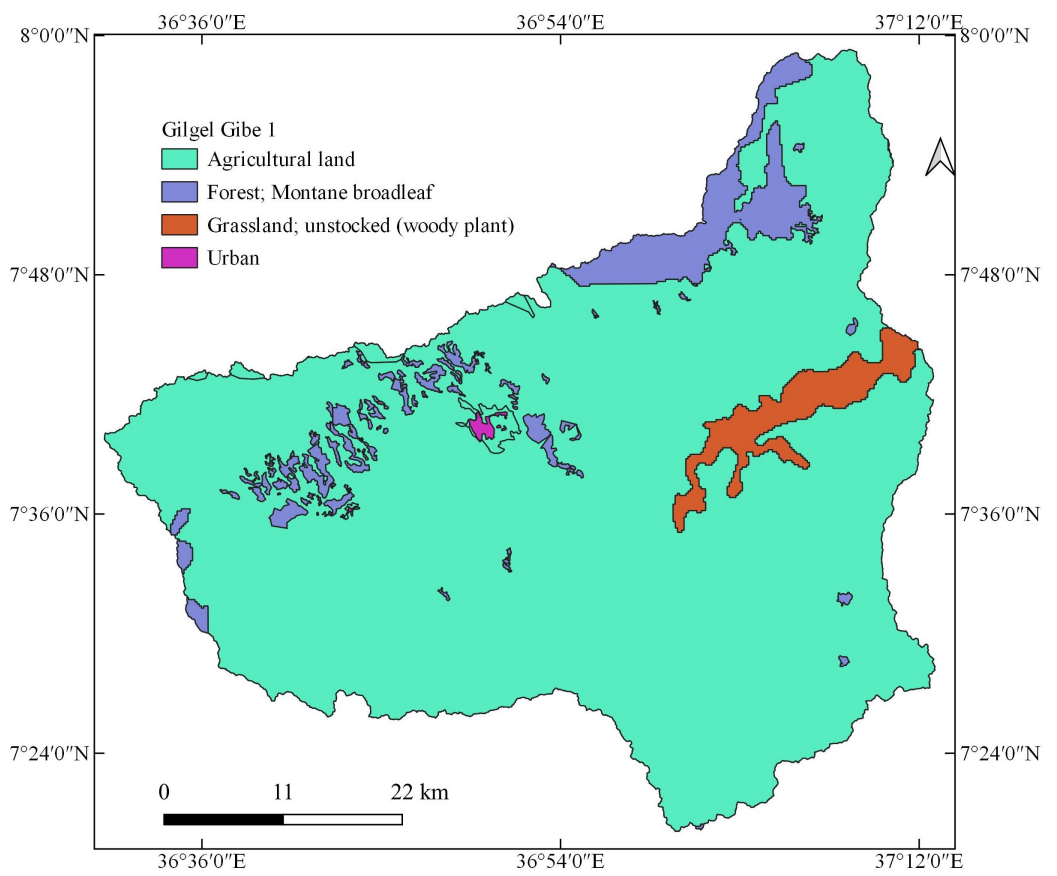

Figure 14. Land use map of Gilgel Gibe 1 Watershed from 1989 to 2009. 


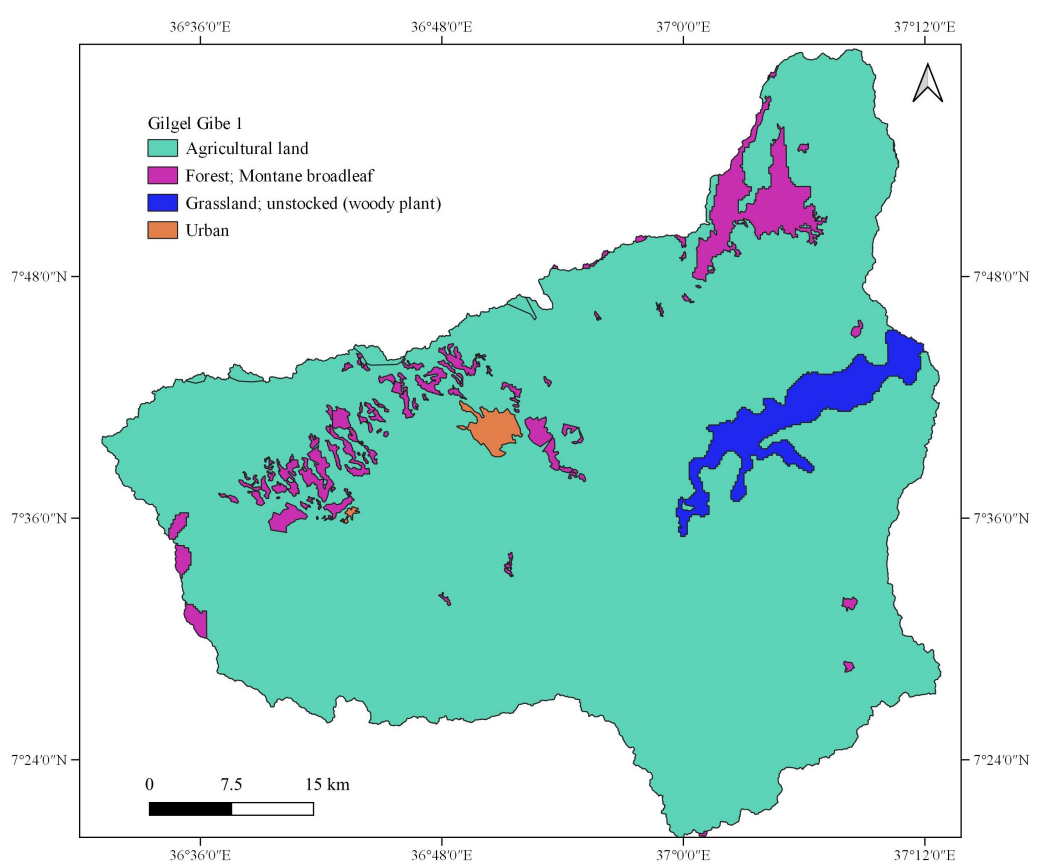

Figure 15. Land use map of Gilgel Gibe 1 Watershed from 2010 to 2015.

\subsection{Sediment rating curves}

A sediment rating curve is required to generate sediment data from corresponding flow data. The linear regression equation and nonlinear regression equations such as power function, the second and third-order polynomial function can be used to model the sediment rating curve(eg.,[96]). Different authors indicate that the power function is a commonly used nonlinear regression approach to model the sediment rating curve(eg., $[88,89,91])$. The power function is given by:

$C=a Q^{b}$

where $C$ is the suspended sediment load or concentration, $Q$ is the discharge, $a$ is the coefficient and $b$ is the exponent. Different authors reviewed physical meanings associated with the coefficient $\mathbf{a}$ and the exponent $\mathbf{b}$ (eg. $[89,94,97])$. Accordingly, the coefficient a represents an index of soil erodibility whereas the exponent $\mathbf{b}$ is considered as an index of erosivity and transport capacity of the river. Thus, the power function can be derived by interpreting or deducting the Modified Universal Soil Loss Equation (MUSLE), where its topographic, soil erodibility, cover and conservation practice factors describe a site-specific condition of a given watershed, and these factors affect the coefficienta of the power function at defined hydro-climatic condition.

For the sake of simplicity of regression analysis, the nonlinear regression equation (in our case, the power function) can be transformed to the simple linear regression equation by log-transform of both sides of the nonlinear equation. Accordingly,

$\log C=\log a+b \log Q$

If $y=\log C$ and $x=b \log Q$ then, $y=a x+b$

The Least Squares and Reduced Major Axis Line (R.M.A.L) regression methods can be applied to find the best-fit regression line on logarithms of suspended sediment load or concentration and discharge data, and back transform of the linear equation results in the power function. To find out the history and conceptual meaning related to the regression analysis and regression methods, readers are encouraged to refer[93,98]. Despite there are no generally accepted procedures to model the sediment rating curve, we proceed with the Least Squares regression method, which is based on the minimum sum of squared errors to estimate the coefficient $\mathbf{a}$ and the constant $\mathbf{b}$ of the best-fit linear regression equation on logarithms of suspended sediment concentration and discharge data. 
$b=\frac{\sum_{i=1}^{n}\left(x_{i}-\bar{x}\right)\left(y_{i}-\bar{y}\right)}{\sum_{i=1}^{n}\left(x_{i}-\bar{x}\right)^{2}}$

$a=\bar{y}-b \bar{x}$

Beside choosing sediment load-discharge [98], logged mean loads within discharge classes [97] or sediment concentration-discharge [96] approaches, correction factors $(y=$ $\left.C F * a Q^{b}\right)($ eg.,[88,97]) and power function with some additive constant can be used $([88,95])$ to improve the sediment rating curve. And also, to improve the sediment rating curve we may check data consistence or homogeneity test in order to find out data classes at specific hydro-climatic condition.

While considering the above advantages and limitations to model the sediment rating curve, the relationship between discharge and suspended sediment concentration rate is checked against land-use change, seasonal weather variations or rainfall pattern, and period of land tillage. Accordingly, the sediment rating curve is drawn while considering rainfall and discharge relationship for Gilgel Gibe 1 watershed, shows some improvement provided that one extreme discharge $319.65 \mathrm{~m}^{3} / \mathrm{s}$ on $8 / 23 / 2009$ (no alike record in the daily average discharge from 1990-2015), which corresponds to the suspended sediment concentration $0.53 \mathrm{~kg} / \mathrm{m}^{3}$, is removed from the records as part of the data quality check. And also, some data replication is possible to improve the sediment rating curve, due to the assumption that two measurements that are taken at very small time differences are almost the same as we only consider a pattern of record rather than a period of record, and also data record does not show watershed information. Accordingly, the sediment rating curve is drawn for the Gumera watershed, showing some improvement (the change in the coefficient of determination is from $R^{2}=0.324$ to $\left.R^{2}=0.5091\right)$ if it is a significant improvement.

For the Hombole and Mojo watersheds, the sediment rating curves are drawn without any pre-conditions. This is because the above pre-conditions do not work for these two watersheds. For the Mojo watershed, two inconsistent records of the rainfall (extremely large and small), flow and sediment on Aug. 7, 1996 and Aug. 6, 2003, are removed from the records as part of the data quality check. Sediment rating curves of all watersheds are given in the figure 16.

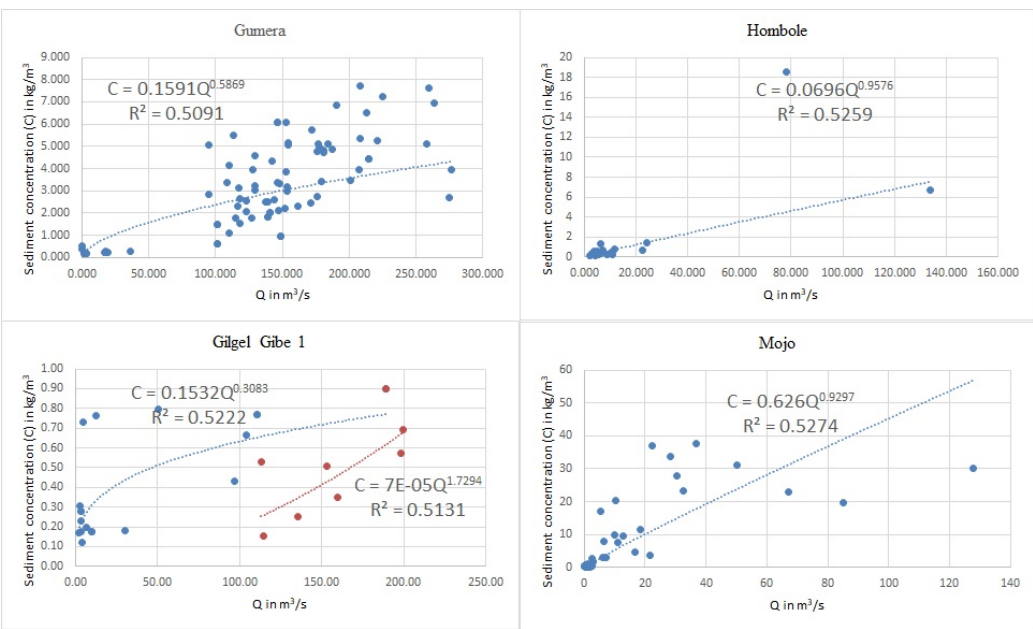

Figure 16. Sediment rating curve for each watershed under our consideration.

\subsection{Estimating factors of the MUSLE}

The original factors of the USLE represent the average value to estimate annual sediment yield. The unit plot ([12]) represents the worst case for the maximum soil erosion at a given rainfall event. It is practically impossible to directly measure each field slope, slope length, temporal variation of soil erodibility, instantaneous runoff, cover change and conservation practice for a large watershed. In the actual field, the field slope and length are not uniform, which means they are irregular. The topographic, soil erodibility, cover and conservation practice factors depend on the spatial resolution of 
the digital elevation model (DEM), soil and land use maps respectively. Therefore, in the actual sediment modelling, average or weighted average of the field slope length [4] and slope steepness or simply topographic factor [3], average daily runoff, average soil erodibility factor [10], and average cover and conservation practice factors are taken to represent complex topography, temporal variation of runoff, temporal and spatial variation soil erodibility, type and density of cover, and type and nature of conservation practice.

Estimation of runoff factor

In the MUSLE, the runoff factor is the product of the total runoff volume and peak runoff rate. Authors [3] reviewed that the runoff factor represents the energy used in transporting as well as in detaching sediment, which acts as the best indicator for predicting sediment yield for the individual storm event. To estimate the runoff factor, the peak runoff rate and/or volume of runoff can be obtained by direct measurement of the runoff on a storm-event basis, and also by using indirect methods such as Soil Conservation Service Curve Number (SCS CN) method, Rational method, flood routing, unit hydrograph, etc. For our case, we used the daily average discharge to estimate the annual total runoff volume and yearly peak runoff rate for the annual sediment yield estimation. The reasons for why we use directly measured flow data and why we estimate the annual sediment yield are addressed in the introduction section.

Estimation of soil erodibility factor (K-factor)

Authors[12] defined soil erodibility factor as the soil loss rate per erosion index unit for a specified soil as measured on a unit plot; the unit plot is defined as a 72.6-ft length of uniform 9-percent slope continuously in clean-tilled fallow; it is the continuous fallow tilled up and down the slope. The soil erodibility factor is given by[12]:

$K=\frac{\sum_{n=1}^{N}(A)_{n}}{\sum_{n=1}^{N}\left(E I_{30}\right)_{n}}$

where $A$ is the event soil loss from the unit plot in tons/acre/year, $E$ is the storm kinetic energy in $100 *$ foot-tons/acre, and $I_{30}$ is the maximum 30 minutes intensity in inch/hour, $K$ is the soil erodibility factor in $0.01 *$ tons $*$ year $*$ acre $*$ hour /acre $*$ foot $*$ tons $*$ inch . It is the important to note that the soil erodibility factor represents the worst or the maximum possible erosion from the unit plot with the specified field slope and length. At the same rainfall impact pressure, less soil erosion condition that is different from the worst condition takes into account the soil cover and conservation practice on the same field slope and length. On the unit plot or any unit plot for that matter, temporal and spatial variation of the soil erodibility depend on types of the soil; quite complex interaction of physical, biological, chemical, and mechanical processes. From the soil erodibility table or equations (see figure17), we can reveal that the soil erodibility factor varies from $0-1$, where 0 indicates the soil that is hard to erode, whereas 1 represents easily erodible soil by the same rainfall impact pressure under otherwise similar soil erosion condition. From this range of the soil erodibility factor, we can conclude that soil erodibility refers to the degree of being easy to erode a given soil.

Soil erodibility factor (K-factor) can be estimated by direct field measurement, or by using different empirical equations or soil erodibility nomograph.

1. The K-factor that was originally developed at soil condition of USA [12]:

$K=\frac{\left\{\left[2.1 * M^{1.14} *\left(10^{-4}\right) *(12-a)\right]+3.25 *(b-2)+2.5 *(c-3)\right\}}{100}$

where $K=$ soil erodibility in $0.01 *$ tons $*$ year $*$ acre $*$ hour /acre $*$ foot $*$ tons $*$ inch; $M=(\%$ silt $+\%$ very finesand $) *(100-\%$ clay $) ; M=$ Particle-size parameter; silt $(\%)=$ percentage of silt; $\%$ very fine sand $=$ percentage of very fine sand $(0.1$ to $0.05 \mathrm{~mm})$; clay $(\%)=$ percentage of clay; $a=$ percentage of organic matter; $b=$ soil structure code used in soil classification, $c=$ profile permeability class. For soils containing less than 70 percent silt and very fine sand, the nomograph [12] is used to solve the above equation.

Some comments on this equation: we do not have a percentage of very fine sand in our database to test the equation. Our source of data is harmonized world soil 
data which includes texture, reference soil depth, drainage class, available water capacity, sand, silt and clay fraction, bulk density, gravel content, organic carbon content, $\mathrm{pH}$, cation exchange capacity, base saturation, total exchangeable bases, calcium carbonate content, gypsum content, sodicity, and salinity content. As land tillage and mechanical compaction (due to rainfall impact)change the structure of the soil; the structure of tilled, bare, or compacted soil varies at temporal and spatial scales. As soil permeability depends on soil texture and organic matter, their relationship should be explicitly shown. Unrealistic values were obtained for tropical soils from the equation's erodibility nomograph (Mulengera and Payton, 1999; Ndomba, 2007) as cited in [8].

2. The K-factor (Williams and Renard, 1983) as cited in[99] and similar equation in $[104,105]$.

$K=\left(0.2+0.3 * \exp \left(-0.0256 * S_{a} *\left(1-\frac{s_{i}}{100}\right)\right)\right) *\left(\frac{S_{i}}{c_{L}+s_{i}}\right)^{0.3} *\left(1-\frac{0.25 c}{c+\exp (3.72-2.95 c)}\right) *$ $\left(1-\frac{0.7 S_{N}}{S_{N}+\exp \left(-5.51+22.9 S_{N}\right)}\right)$

where $S_{a}=$ sand (\%); $S_{i}=\operatorname{silt}(\%) ; C_{L}=\operatorname{clay}(\%) ; S_{N}=1-\left(S_{a} / 100\right) ; C=$ organic carbon

3. The K-factor that was tested at soil condition of the Philippine [100]:

$K=\left[0.043 * p H+\frac{0.62}{O M}+0.0082 * S-0.0062 * C\right] * S i$

where $\mathrm{pH}=\mathrm{pH}$ of the soil; $O M=$ organic matter $(\%) ; S=$ sand content $(\%) ; C=$ clay ratio $=\%$ clay $/(\%$ sand $+\%$ silt $) ; S i=$ silt content $=\%$ silt $/ 100$

4. The K-factor that was originally developed at volcanic soil of Hawaii, USA (ElSwaify and Dangler, 1976) as cited in[20]:

$K=-0.03970+0.00311 * x_{1}+0.00043 x_{2}+0.00185 x_{3}+0.00258 x_{4}-0.00823 x_{5}$ where $x_{1}$ : unstable aggregate size fraction $(<0.250 \mathrm{~mm})(\%) ; x_{2}=$ modified silt $(0.002-0.1 \mathrm{~mm})(\%) *$ modified sand $(0.1-2 \mathrm{~mm})(\%) ; x_{3}$ : \% base saturation; $x_{4}$ : silt fraction $(0.002-0.050 \mathrm{~mm})(\%) ; x_{5}$ : modified sand fraction $(0.1-2 \mathrm{~mm})(\%)$.

comment: we do not have unstable aggregate size fraction or modified silt and sand data in our database to test the equation.

5. Williams (1995) proposed the following K-factor as cited in [106]:

$$
\begin{aligned}
& K=f_{\text {csand }} * f_{c l-s i} * f_{\text {orgC }} * f_{\text {hisand }} \\
& f_{\text {csand }}=0.2+0.3 \exp \left[-0.256 m_{s}\left(1-\frac{m_{\text {silt }}}{100}\right)\right] \\
& f_{c l-s i}=\left(\frac{m_{\text {silt }}}{m_{c}-m_{\text {silt }}}\right)^{0.3} \\
& \text { forgC }=1-\frac{0.25 * \text { orgC }}{\text { orgC }+\exp [3.72-2.95 \text { orgC }]} \\
& f_{\text {hisand }}=1-\frac{0.7\left(1-\frac{m_{s}}{100}\right)}{1-\frac{m_{s}}{100}+\exp \left[-5.51+22.9\left(1-\frac{m_{s}}{100}\right)\right]}
\end{aligned}
$$

6. other soil erodibility's equations are mentioned in [20,101,105-109,112].

To test the soil erodibility equations on the basis of the original definition of the soil erodibility by [12], the following conditions should be fulfilled. From the MUSLE, $K=\frac{y}{a(Q q)^{b} * L S C P}$

where, $K$ represents the worst condition for the maximum erosion case when the slope field length is $22.13 \mathrm{~m}$ and the slope angle is $9 \%$. In this case, no cover and conservation practices are employed in the field to give protection against soil erosion; the land is tilled up and down the slope, and therefore, the maximum erosion is expected. In the above equation, $K$ represents the maximum erosion case when observed sediment yield $(y)$ is due to soil erosion from a field with a specified slope length, slope angle, cover and conservation practice. If we take $C=P=1, K$ represents the maximum erosion from the field with the specified slope length and angle. However, our observed sediment yield does not represent the worst conditions for the maximum erosion case; we have some magnitude of cover and soil conservation practice to give protection against soil erosion, and land is not tilled up and down the slope. Therefore, in this case, $K$ represents the minimum value as compared to the actual value that will be obtained from the soil erodibility equation for the worst conditions for the maximum soil erosion case $\left(K_{e q}\right)$. 
$K_{\text {min }}=\frac{y}{L S a Q^{b}}<<k_{e q}$

For our watersheds, the minimum $K$ value is calculated by replacing the annual sediment load, runoff volume, and topographic factor (the reasons for why we use the annual erodility factor are given in the introduction section). Based on the soil data we have, the actual soil erodibility factor is calculated by using the soil erodibility equations that were proposed by [106], [100], and Williams and Renard (1983) as cited in [99]. Accordingly, the graphs of the K-factor are shown in the figure 17.

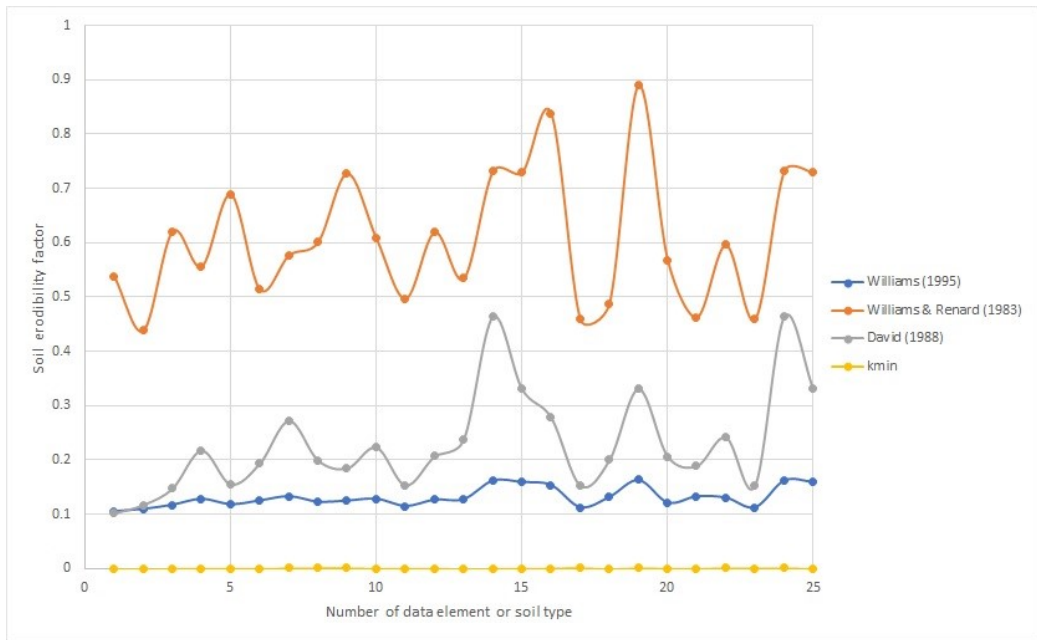

Figure 17. K-factor graphs of different soil types, which represent any of four watersheds under our consideration.

From the graph, a reasonable actual erodibility graph for our watersheds lies between the minimum K-factor graph and the calculated K-factor using Williams's (1995) equation as cited in [106]. To proceed with Williams's (1995) equation as cited in [106], Williams's sub K-factors are calculated and compared based on silt and sand content, clay and silt continent, and organic carbon content of our soil data. In comparative speaking, soil erodibility increases if silt content increases, and sand and clay content decreases. This is because the interaction between soil particles ranges from the loose interaction for silt soil to the strong interaction for clay soil. Humus, manure, organic matter, or organic carbon content decreases soil erodibility as it binds the soil particles together, or it provides protective cover for soil particles. 

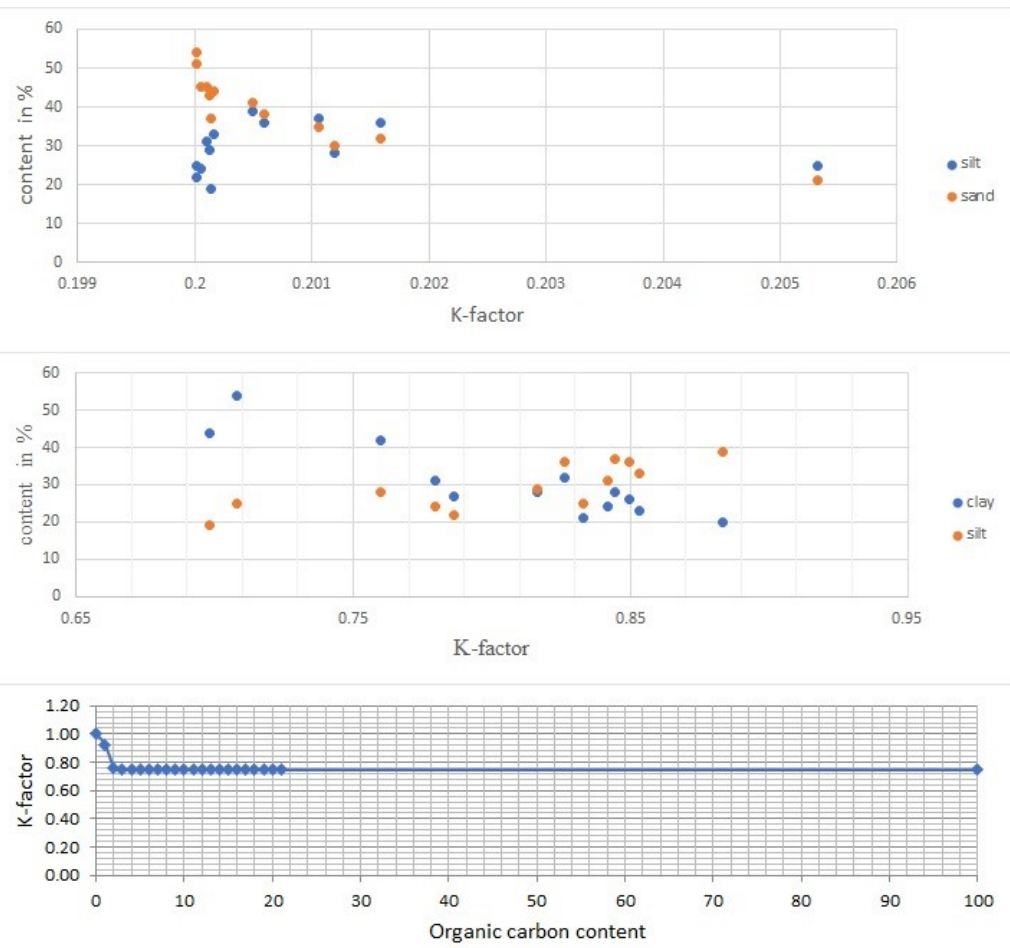

Figure 18. Comparison of sub K-factors based on soil data, which represent any of four watersheds under our consideration.

From figure18, the soil erodibility factors conform to the general comparisons stated above. Therefore, we use Williams's (1995) equation as cited in [106] to calculate the soil erodibility factor using soil data of the watersheds under our consideration, watersheds of Ethiopia in general.

\section{Estimation of slope steepness and slope length factors}

Slope steepness factor (S) is the ratio of soil loss from a field slope gradient to soil loss from the $9 \%$ slope under otherwise identical conditions[15]. A high rate of soil loss is associated with steep slopes $([10,19]$, and soil loss prediction is more sensitive to the slope steepness than slope length[110].

Slope length is defined as the distance from the point of origin of overland flow to the point where either the slope gradient decreases enough that deposition begins, or the runoff water enters a well-defined channel that may be part of a drainage network or a constructed channel [12]. It is important to note that the definition of the slope length relies on the conditions at which the unit plot was constructed by [12]; the unit plot represents the worst condition for the maximum soil erosion case. Therefore, for the worst condition for the maximum erosion case, the slope length is the shortest distance from the origin of overland flow to the point where deposition takes place or enters stream channels. The slope lengths would rarely have a constant gradient along their entire length, and the slope irregularities would affect the amount of soil movement to the foot of the slope [12]. The slope length factor is given by[12]:

$L=\left(\frac{\lambda}{\lambda_{0}}\right)^{m}$

where $\lambda$ is the slope length; $\lambda_{0}$ is the unit plot length $=72.6 \mathrm{ft}=22.13 \mathrm{~m} . \lambda_{0}$ is also defined as the horizontal projection of slope length (eg., [16-19]). In one term, slope steepness factor (S) and slope length factor (L) together is called as topographic factor (LS-factor). The topographic factor is the ratio of soil loss per unit area from a field slope length and gradient to that from the $22.1 \mathrm{~m}$ length of uniform $9 \%$ slope under otherwise 
identical conditions [12]. Different equations have been suggested at different locations to estimate the topographic factor while taking into account site-specific conditions.

1. Topographic factor that was developed at the topographic condition of USA[12]: $L S=\left(\frac{\lambda}{72.6}\right)^{m}\left(65.41 \sin ^{2} \theta+4.56 \sin \theta+0.065\right)$

where $\lambda=$ slope length in feet; $\theta=$ angle of slope; $m=$ dependent on the slope $(0.5$ if slope $>5 \%, 0.4$ if slope is between $3.5 \%$ and $4.5 \%, 0.3$ if slope is between $1 \%$ and $3 \%, 0.2$ if slope is less than $1 \%$ ).

2. McCool et al. (1987) improved the LS factor from classic USLE for use in terrain with steeper slopes as cited in[3], for use in RUSLE[19]:

$$
\begin{aligned}
& L=\left(\frac{\lambda}{22.13}\right)^{m} \\
& m=\frac{\sin \theta}{\sin \theta+0.269(\sin \theta)^{0.8}+0.05} \\
& S=3.0(\sin \theta)^{0.8}+0.56 \text { for } \lambda<4 m \\
& S=10.8 * \sin \theta+0.03 \text { for } \lambda>4 \text { mands }<9 \% \\
& S=16.8 \sin \theta-0.50 \text { for } \lambda>4 \text { mands }>9 \%
\end{aligned}
$$

where $\lambda$ is the slope length in meters, $\mathrm{m}$ is the dimensionless parameter, $\theta$ is angle of field slope in degrees $=\tan -1(\mathrm{~s} / 100)$ and $\mathrm{s}$ is the field slope in percent.

3. Foster et al., $(1977)$ and McCool et al., $(1987,1989)$ proposed the following equations for the calculation of the LS factors as cited in[20]

$L=\left(\frac{\lambda}{72.6}\right)^{m}$

$m=\frac{\beta}{1+\beta}$ (Foster et al.,1977) as cited in[20]

$\beta=\frac{\frac{\sin \theta}{0.0896}}{3.0 *(\sin \theta)^{0.8}+0.56}$ (McCool et al., 1989) as cited in[20]

$S=10.8 * \sin \theta+0.03$ if slope (s) is less than $9 \%$ (McCool et al., 1987) as cited in[20]

$s=16.8 \sin \theta-0.5$ if slope is greater than or equal to $9 \%$ ( McCool et al, 1987) as cited in[20]

$S=3.0 *(\sin \theta)^{0.8}+0.56$ if the slope length is shorter than $4.6 \mathrm{~m}$ (McCool et al., 1987) as cited in [20], for the condition where water drains freely from slope end, and it is assumed that inter-rill erosion is insignificant on slopes shorter than 4.6 $\mathrm{m}$ [19]. Where $\lambda$ is the slope length (ft); $\theta$ is the angle of slope; $m$ is the dependent on the slope ( 0.5 if slope $>5 \%, 0.4$ if slope is between $3.5 \%$ and $4.5 \%, 0.3$ if slope is between $1 \%$ and $3 \%, 0.2$ if slope is less than $1 \%$ ). As a remark, when conditions favour more inter-rill and less rill erosion, as in cases of consolidated soils like those found in no-till agriculture, $m$ should be decreased by halving the $\beta$ value, where a low rill to inter-rill erosion ratio is typical of conditions on rangelands ([19]). With thawing, and cultivated soils dominated by surface flow, a constant value of 0.5 should be used (McCool et al., 1989, 1993) as cited in[19]. When freshly tilled soil is thawing, in a weakened state, and primarily subjected to surface flow, we use the following (McCool et al., 1993) as cited in [19].

$S=10.8 \sin \theta+0.03 s<9 \%$

$S=\left(\frac{\sin \theta}{0.0896}\right)^{0.6} \quad S>9 \%$

4. The slope factor which is approximately equal to the LS factor at the topographic condition of the Philippines[100].

$S=a+b * S_{L}^{4 / 3}$

where $\mathrm{S}$ is slope factor, $\mathrm{a}=0.1 ; \mathrm{b}=0.21 ; \mathrm{SL}=$ slope $(\%)$

5. The LS factor was developed at the topographic condition of Britain[102]:

$L S=\left(\frac{\lambda}{22}\right)^{0.50} *\left(0.065+0.045 s+0.0065 s^{2}\right)$

where $\lambda$ is the slope length (m); $\mathrm{s}$ is the slope steepness (\%)

6. Apart from the LS factor of the USLE/RUSLE, the Chinese Soil Loss Equation[21] was developed while taking into consideration the Chinese soil environment and 
topographic conditions (including the modified equation that can calculate LS factor in $>10^{\circ}$ conditions) [13]. In the Chinese soil loss equation, the LS factor is calculated by [13].

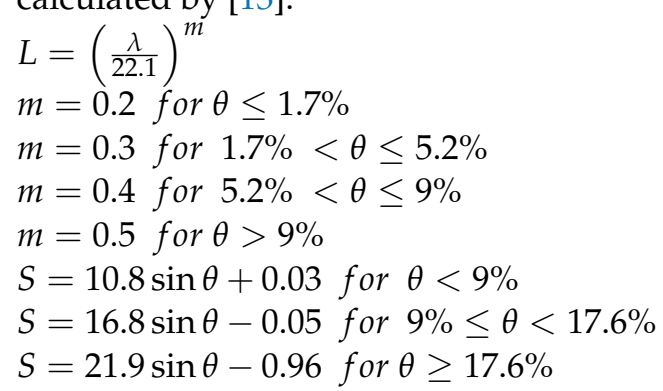

where $\lambda$ is the slope length (m), $\mathrm{m}$ is the variable slope-length exponent, and $\theta$ is the slope angle $\left(^{\circ}\right)$.

7. other equations of the slope or slope length factor are mentioned in[3,7,13,21,103, 110,111].

To estimate the topographic factor for our watersheds, SWATplus is used to define as many hydrologic response units (hrus) as possible to consider an areal distribution of the slope steepness and slope length. In the TxtInOut folder of the SWATplus, area and topography information of each hru are stored in the hru and topography files respectively. These files are exported to an excel spreadsheet for analysis. The area, slope, and slope length of each hru are used to estimate the LS factor for each hru by using the above equations and the equations 1 and 2 stated below. The weighted average of the LS factors is taken to represent the watershed (it is important to note that the sediment or flow routing techniques in the SWATplus are not employed in this paper due to one or more reasons stated in the introduction section). The best-fit methods are chosen during the calibration of the annual sediment yield (see the calibration stage below).

\section{Estimation of cover factor (C-factor)}

It is the ratio of soil loss from a field with specified cropping to that from clean-tilled, continuous fallow under otherwise similar conditions. These similar conditions are; no soil conservation works (land is tilled up and down the slope), soil, slope steepness, slope length, and rainfall impact pressure is the same for both cropped field and fallow area. The C-factor is related to the land use and land cover, and it is the reduction factor to soil erosion vulnerability[14]. Therefore, the C-factor lies between 0 and 1, which describes the extent of vegetation cover to protect soil from erosion in a given catchment. Its value closer to 0 indicates dense vegetation cover, whereas its value closer to 1 indicates poor vegetation cover. Essentially, surface cover or canopy protects soil erosion by decreasing rainfall impact energy, but it may have less importance to protect sediment transport from the field. To some extent, we can say that surface cover affects erosion by reducing the transport capacity of the runoff water (Foster, 1982), and by causing deposition in ponded areas (Laflen, 1983) as cited in [20], and also by decreasing the surface area susceptible to raindrop impact [20]. In addition, plant root depth and distribution, and porosity increase the infiltration rate of the rainfall water into the soil, and thus they play a role in reducing soil loss(Jeong et al. 2012) as cited in[113].

Although C-factor value can be taken from the literature or determined in situ, an extensive literature review compiling potential soil loss rates of different crop and forest covers compared to likely soil loss rates of bare soil can be used to determine likely C-factor values of a particular site [7]. The published guidelines[12,19], the revised C-factor (Cai et al., 2000) as cited in[114] and the Normalized Difference Vegetation Index $([109,112]$ can be used to compute C-factor. For our case, the annual or average annual cover factor for each land use category is adopted based on the assessment of literature. Authors [7] reviewed C-factors for general types of land use and land cover. For our watersheds, the adopted cover factor for each land use is shown in the table 1. To estimate an areal weighted average of the cover factor for our watersheds, SWATplus 
is used to define as many hydrologic response units (hru) as possible to consider areal distributions of land use and land cover. In the TxtInOut folder of the SWATplus, the area of each hru is stored in the hru file, and hru's land use data files are stored in the hru-data file. These files are exported to an excel spreadsheet for analysis and calculation of the areal weighted average. We can use the shapefile of each land use map (see figure $8,9,10,11,12,13,14$ and 15) to estimate areal coverage of each land use classes in QGIS, and then the corresponding $C$ and P-factors can be assigned.

Table 1. The assigned cover and conservation practice factors for each land use of the watersheds under our consideration

\begin{tabular}{|c|c|c|}
\hline Land-use category & C-factor & P-factor \\
\hline Acacia & 0.01 & 1 \\
\hline Acacia Bushland/Thicket & 0.01 & 1 \\
\hline Acacia Shrubland/Grassland & 0.01 & 1 \\
\hline Agricultural land & 0.525 & 0.52 \\
\hline Bare Land & 1 & 1 \\
\hline Dispersed Acacia & 0.01 & 1 \\
\hline Dispersed Shrub & 0.01 & 1 \\
\hline Eucalyptus & 0.001 & 1 \\
\hline Fir/Cedar Forest & 0.001 & 1 \\
\hline Forest & 0.001 & 1 \\
\hline Forest; Montane broadleaf & 0.001 & 1 \\
\hline Grassland & 0.01 & 1 \\
\hline Grassland, Herbaceous Wetland & 0.01 & 1 \\
\hline Grassland; unstocked (woody plant) & 0.01 & 1 \\
\hline Herbaceous Wetlands & 0.01 & 1 \\
\hline Montane Broadleaf Evergreen Woodland & 0.001 & 1 \\
\hline Rocky Bare Land & 1 & 1 \\
\hline Secondary Semi-deciduous Forest/Woodland & 0.001 & 1 \\
\hline Semi-Desert Grassland with Shrubland & 0.01 & 1 \\
\hline Shrubland & 0.01 & 1 \\
\hline Tropical Forest & 0.001 & 1 \\
\hline Plantations & 0.001 & 1 \\
\hline Tropical Plantations & 0.001 & 1 \\
\hline Urban & 0 & 1 \\
\hline Water Bodies & 0 & 0 \\
\hline Wetland & 0.01 & 1 \\
\hline Woodland & 0.01 & 1 \\
\hline
\end{tabular}

Estimation of soil conservation /erosion control practice factor (P-factor)

It is the ratio of soil loss associated with a specific support practice to the corresponding soil loss when cultivation is done up and down the slope [20] under otherwise similar conditions. The P-factor describes the effects of practices such as contouring, strip cropping, concave slopes, terraces, grass hedges, silt fences, straw bales, and subsurface drainage [14]. These conservation practices change the direction and speed of runoff [19]; it mainly reduces the transport of soil particles by blocking runoff and breaking its speed, but it does not reduce rainfall impact energy to reduce soil erosion. Therefore, the P-factor ranges from 0 to 1 , where 0 represents the strong conservation practice (no soil loss from the field is expected), whereas 1 represents the worst condition for the maximum erosion due to lack of conservation practice and when land is tilled up and down the slope, and runoff takes the shortest well-defined channel or route in the field.

The difficulty of accurately mapping support practice factors or not observing support practices leads to many studies ignoring it by giving their P-factor a value of 1.0 [7]. Some P-factors can be ignored if some C-factors already account for the presence of a support factor such as intercropping or contouring [7]. All non-agricultural lands were also assigned a value of 1 if no feasible conservation measures were applied [10,113,114]. At suitably detailed scales and with enough knowledge of farming practices, using the 
P-factor may lead to a more accurate estimation of soil loss [7]. Authors[5] reviewed that considering the temporal variation of the P-factor could significantly improve the performance of the MUSLE, although it has been rarely taken into account. The soil conservation or erosion control practice factors can be estimated with the help of available tables [12], using land use and land cover maps [10,113,114] and through field measurement (see literature review report in [5]. For our case, the annual soil conservation practice factor for each land use category is adopted based on the assessment of literature. Authors [7] reviewed P-factors for general types of land use and land cover. The adopted P-factor for land use and land cover category of each watershed is shown in the table 1 . The areal weighted average of the P-factor is done in the same way as the cover factor.

\section{Estimation of coefficient $a$ and exponent $b$ through calibration}

For a chosen value of the exponent $\mathbf{b}$, the best-fit corresponding value of the coefficient $\mathbf{a}$ is estimated through calibration. The selection of the best exponent and the best equation among listed above and below (see equations 1 and 2) for the topographic factor is done after calibration of observed and simulated sediment (i.e MUSLE is used to estimate sediment load). The figure 19 shows sample graphs of the sediment calibration when the topographic factor is calculated using the equation that was proposed by [12].

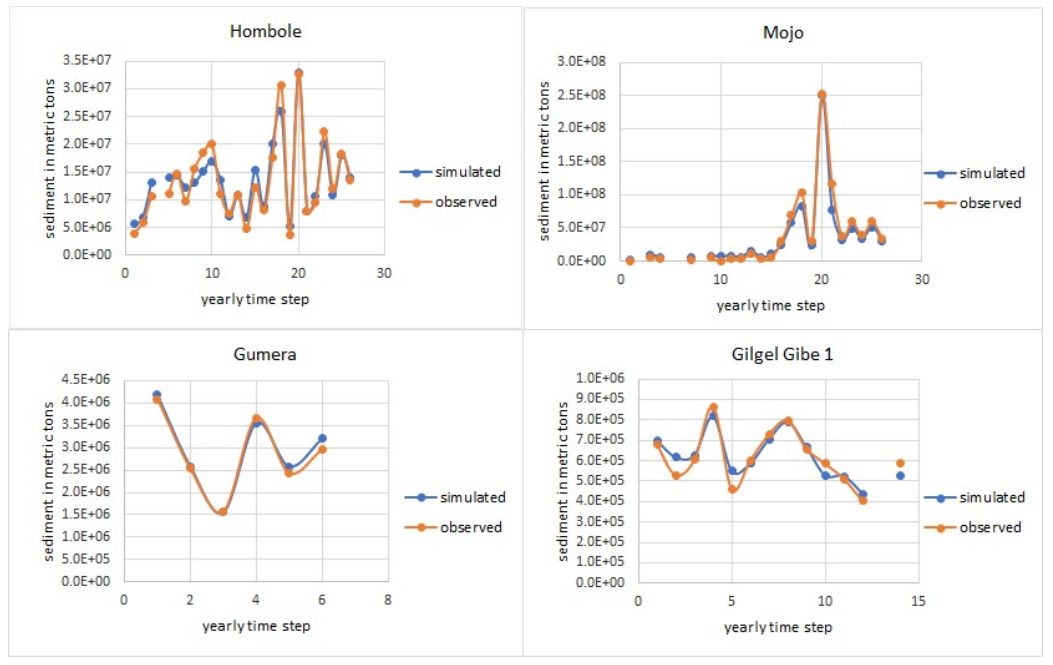

Figure 19. Observed and simulated sediment.

During calibration, Nash-Sutcliffe efficiency corresponds to each LS factor, the exponent $\mathbf{b}$ and the coefficient $\mathbf{a}$ is evaluated, and graphs of the exponent $\mathbf{b}$ versus Nash-Sutcliffe efficiency, and graphs of the coefficient $\mathbf{a}$ versus exponent $\mathbf{b}$ are drawn for each watershed, as shown in the figures $20,21,22,23,24,25$ and 26 . For a chosen value of $\mathbf{b}$, we test seven different equations of the topographic factor for each watershed. Therefore, we can have as many graphs as possible. 


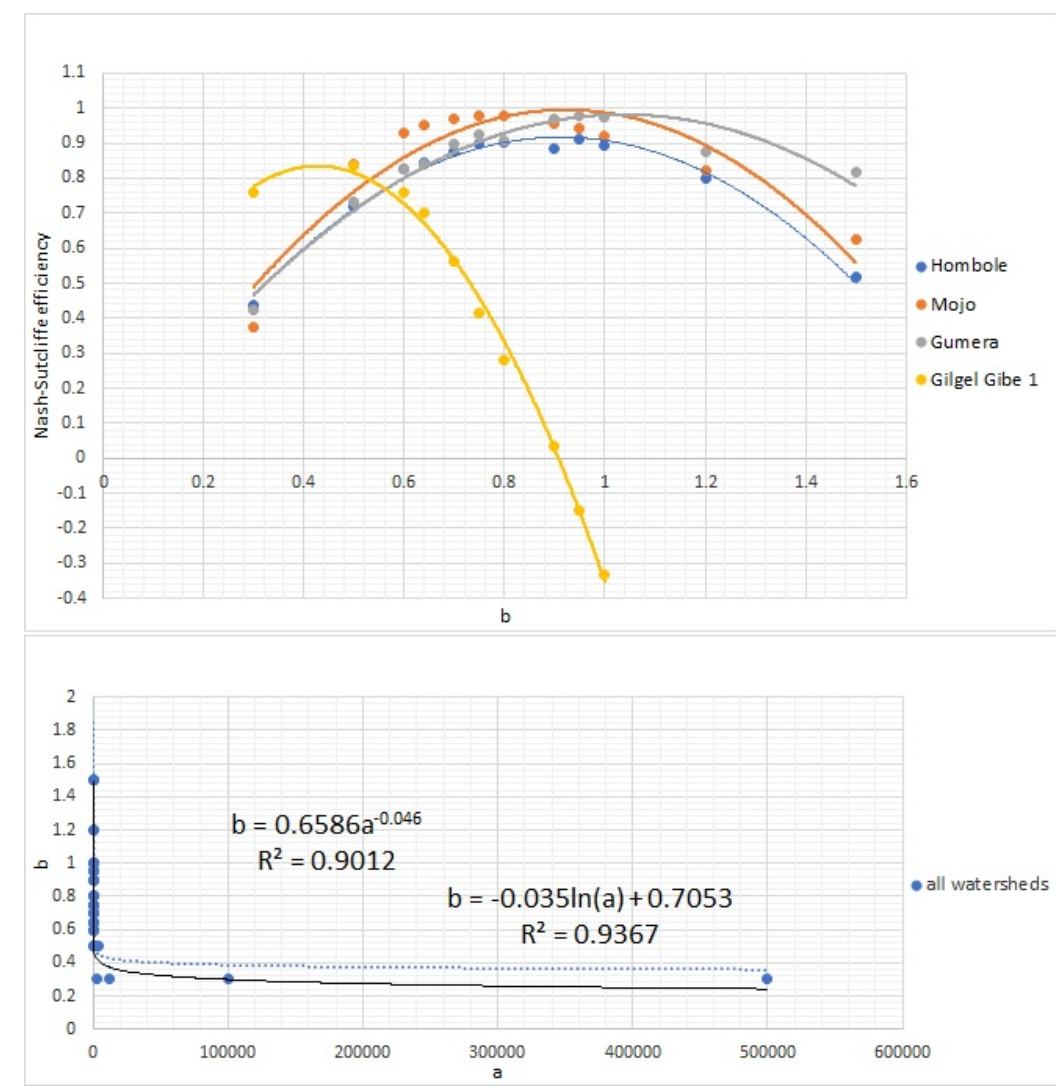

Figure 20. The relationship between exponent $\mathbf{b}$ versus Nash-Sutcliffe efficiency, and the coefficient a versus the exponent $b$ when the topographic factor is calculated by using the equation that was proposed by [12]. 


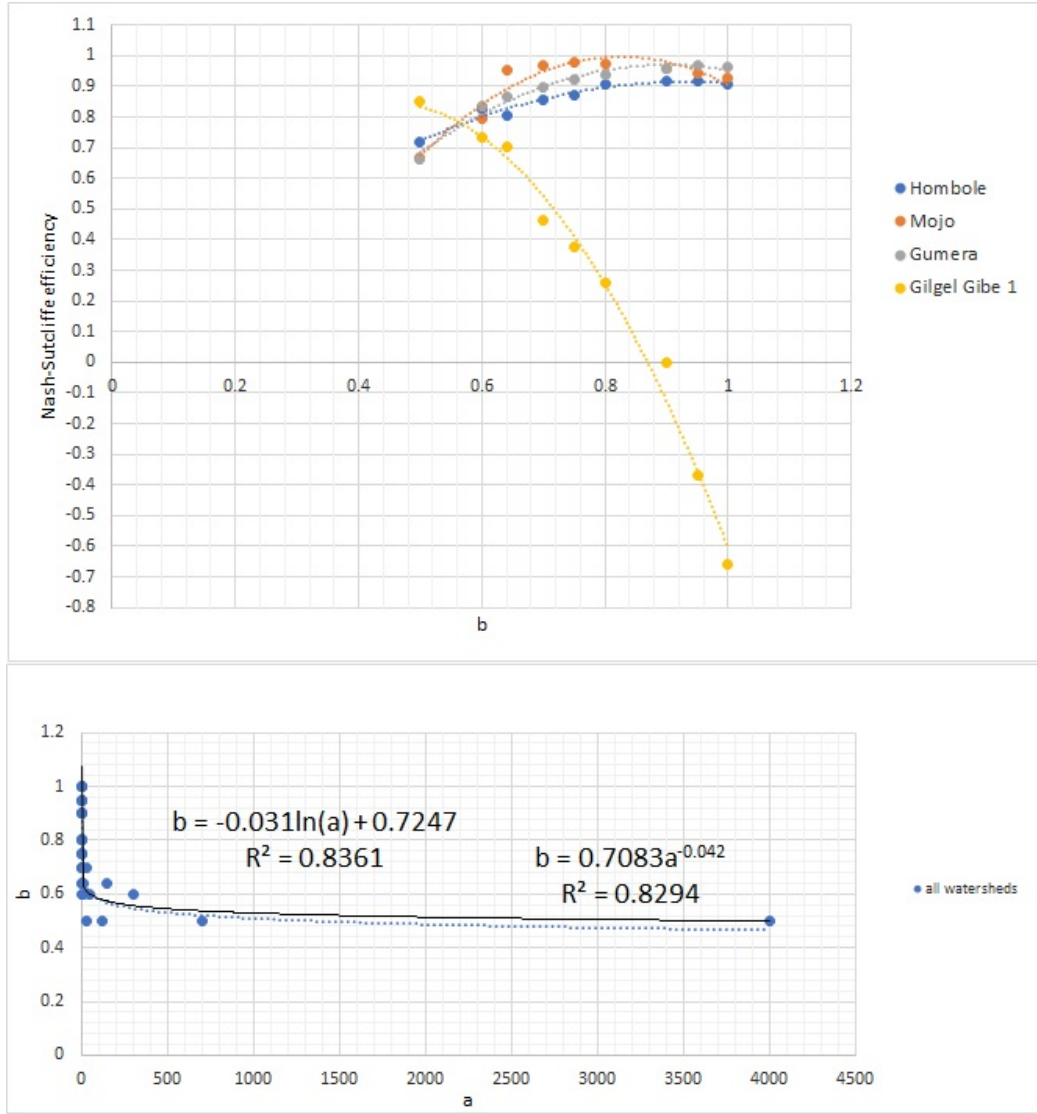

Figure 21. The relationship between exponent $\mathbf{b}$ versus Nash-Sutcliffe efficiency, and the coefficient a versus the exponent $\mathbf{b}$ when the topographic factor is calculated by using the equation that was proposed by [20]. 


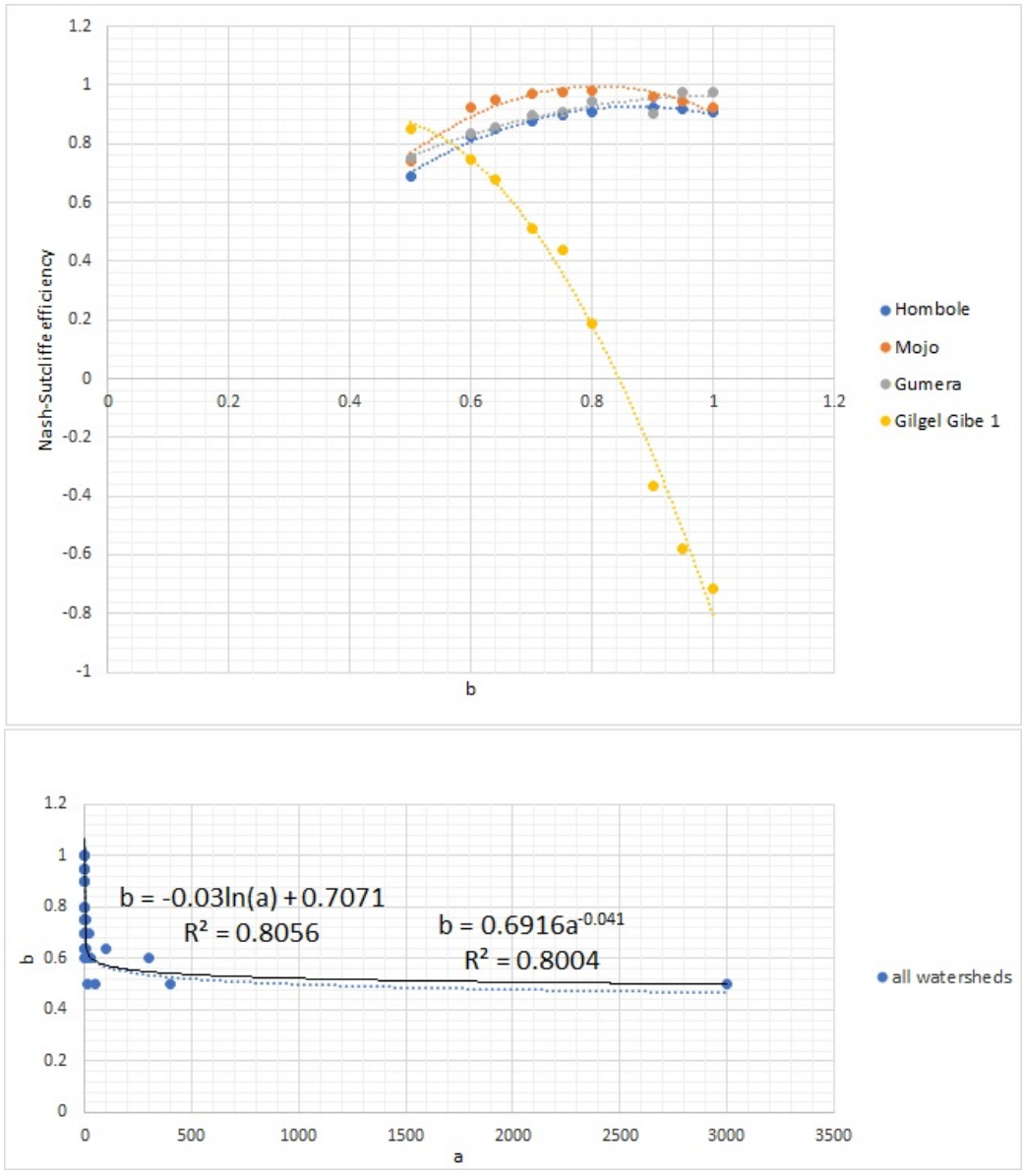

Figure 22. The relationship between exponent $\mathbf{b}$ versus Nash-Sutcliffe efficiency, and the coefficient a versus the exponent $\mathbf{b}$ when the topographic factor is calculated by using the equation that was proposed by [102]. 


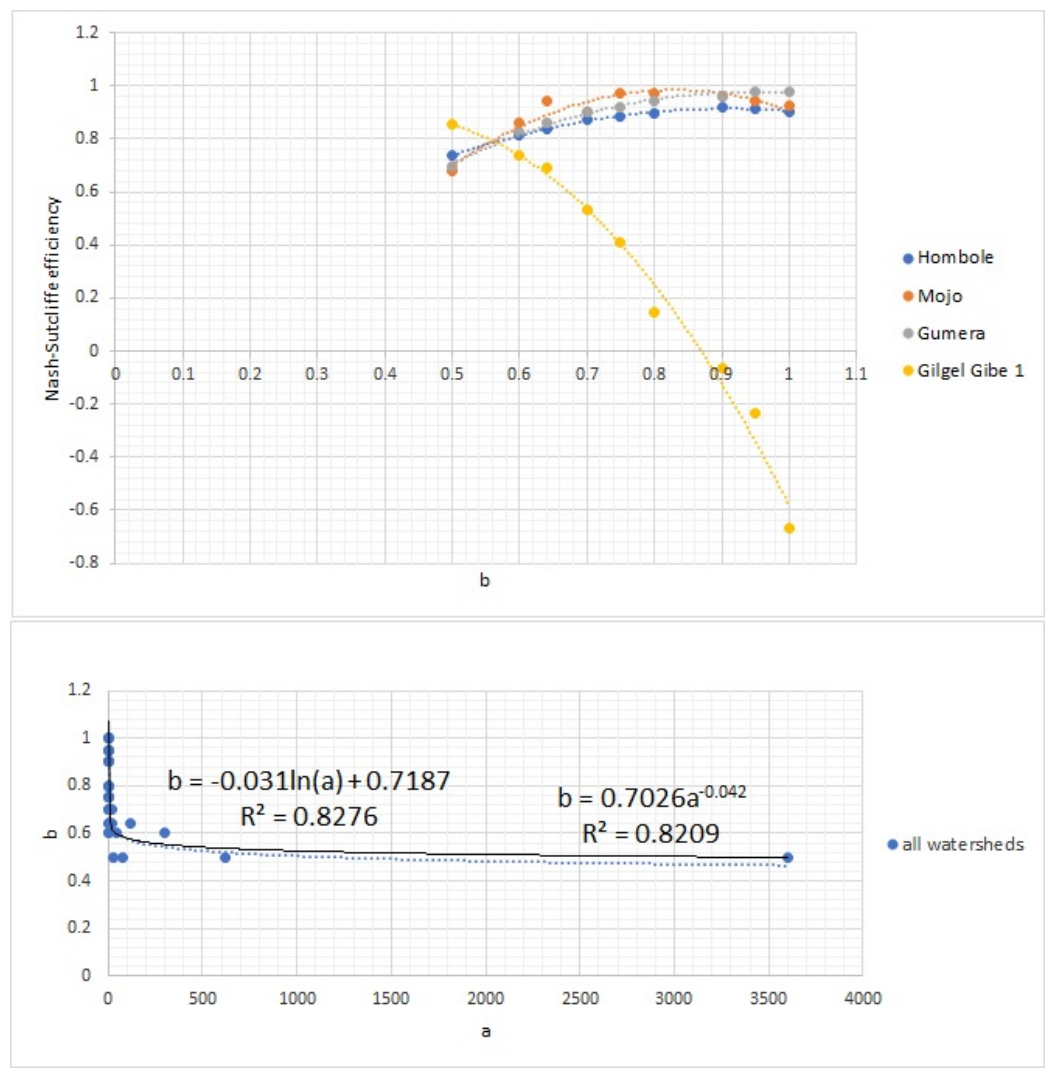

Figure 23. The relationship between exponent $\mathbf{b}$ versus Nash-Sutcliffe efficiency, and the coefficient a versus the exponent $\mathbf{b}$ when the topographic factor is calculated by using the equation that was proposed by McCool et al., (1987) as cited in [3]. 


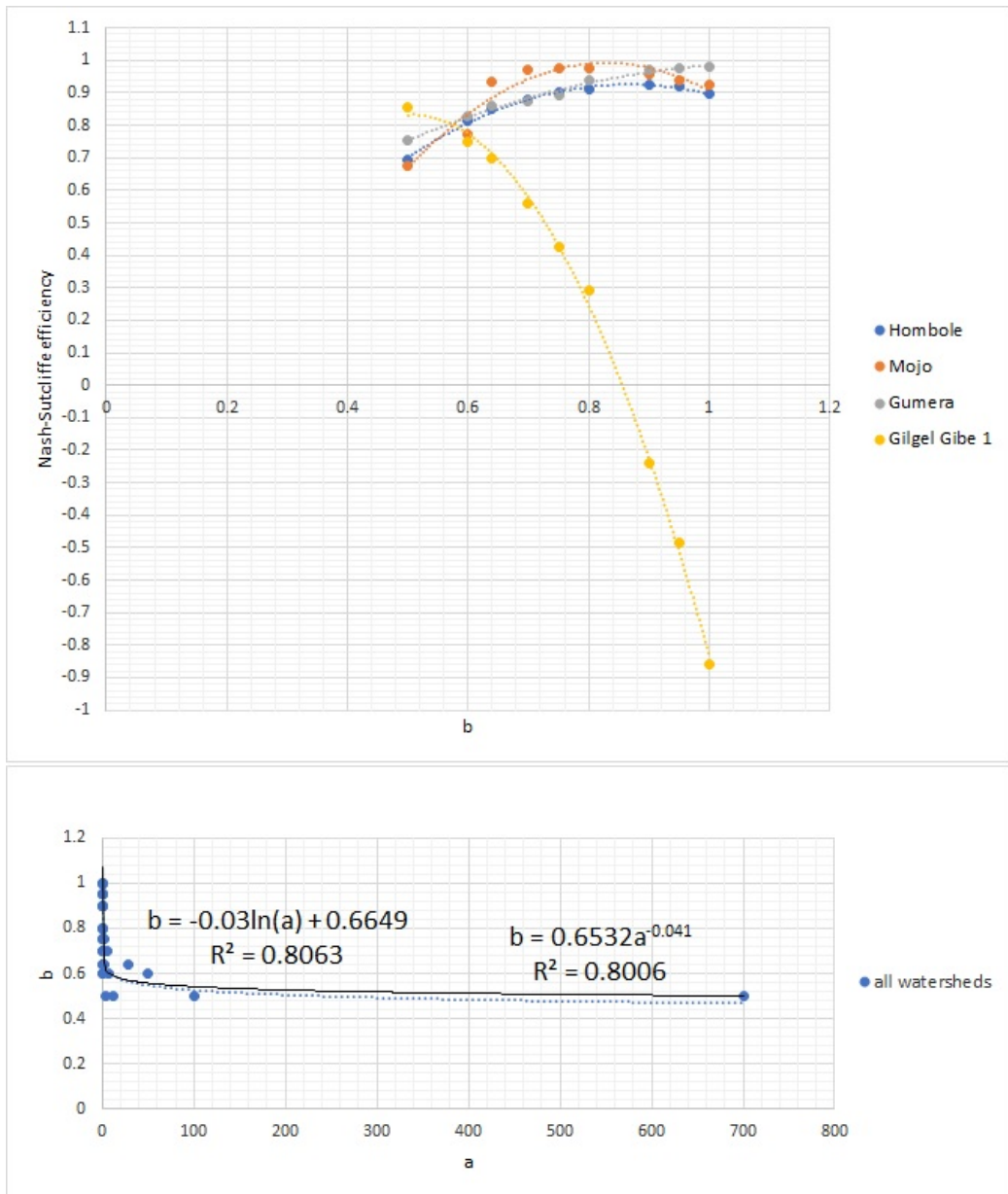

Figure 24. The relationship between exponent $\mathbf{b}$ versus Nash-Sutcliffe efficiency, and the coefficient a versus the exponent $b$ when the topographic factor is calculated by using the equation that was proposed by[100]. 

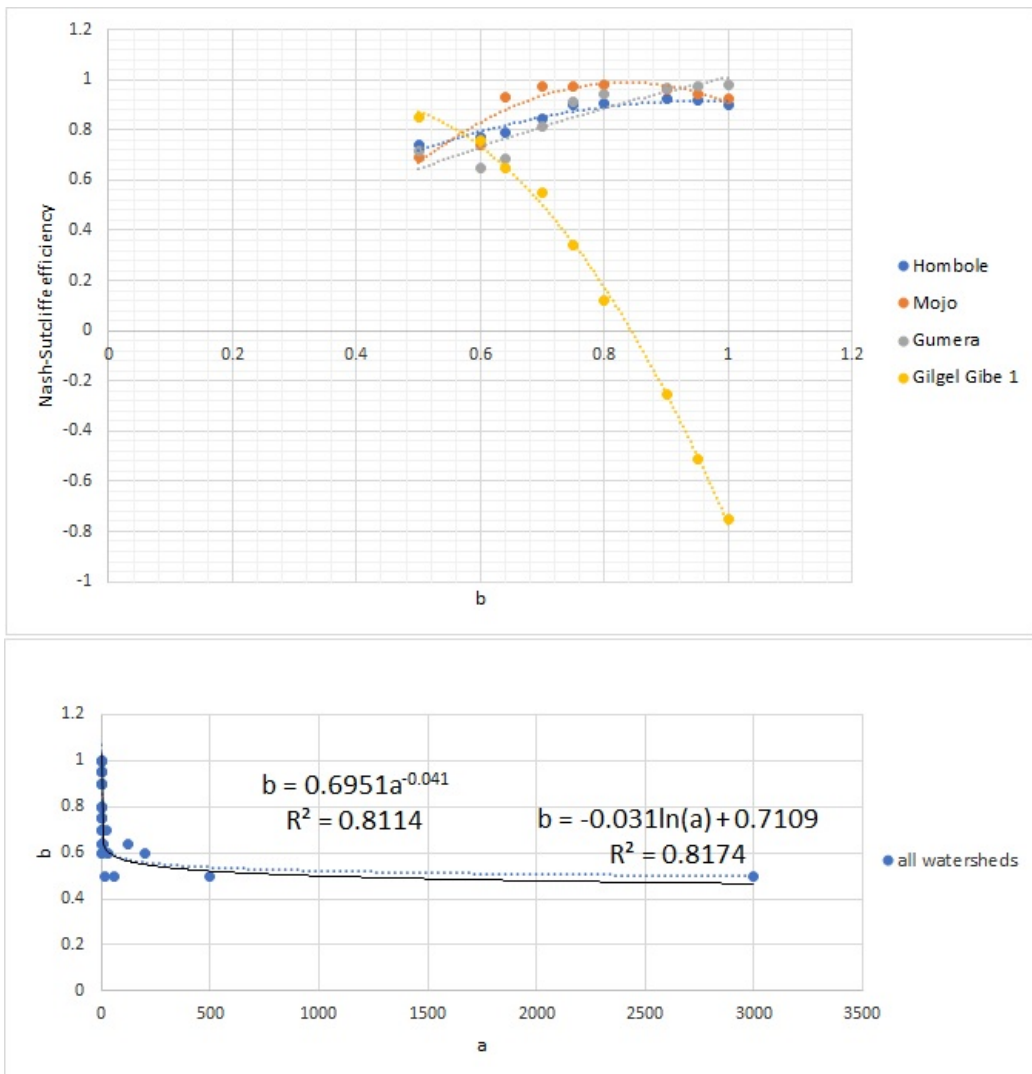

Figure 25. The relationship between exponent $\mathbf{b}$ versus Nash-Sutcliffe efficiency, and the coefficient a versus the exponent $\mathbf{b}$ when the topographic factor is calculated by using the Chines equation.

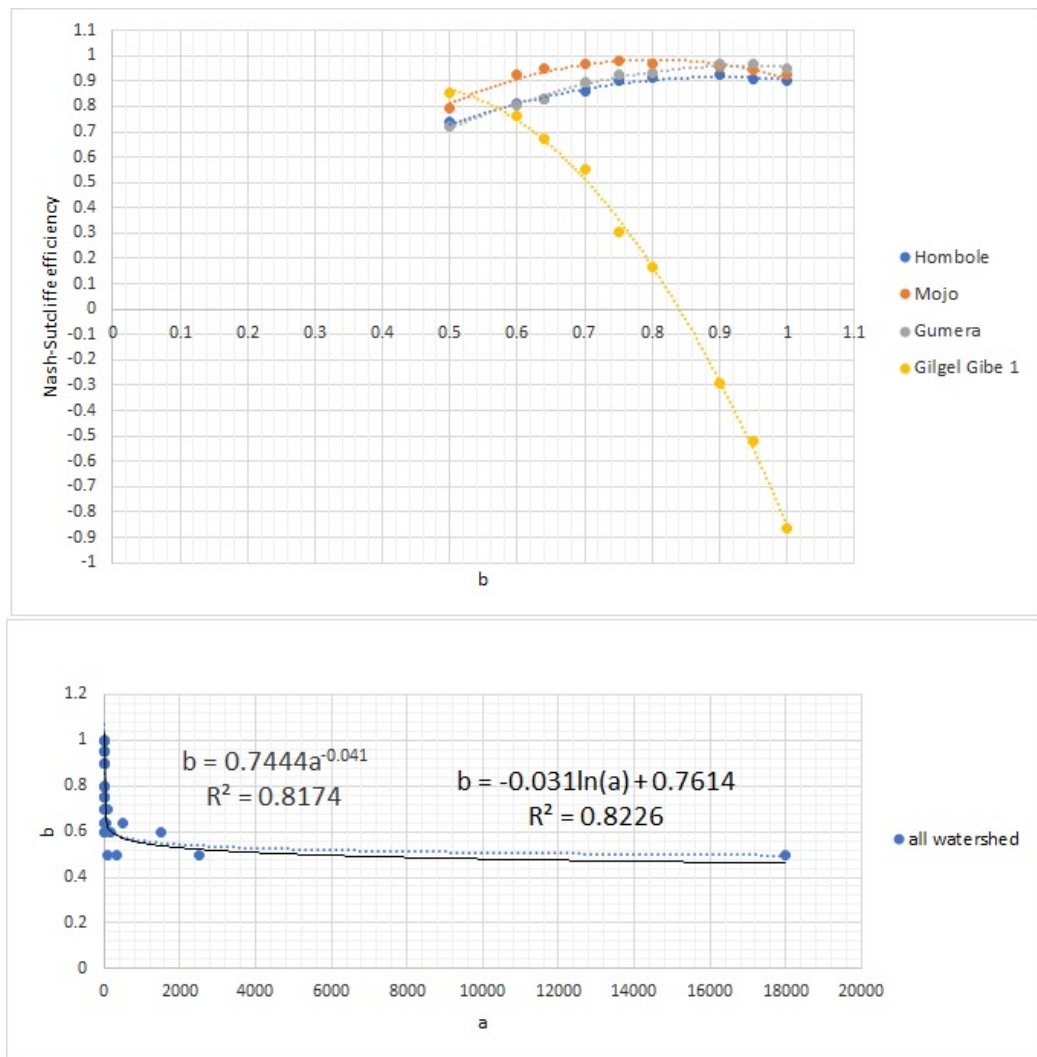

Figure 26. The relationship between exponent $\mathbf{b}$ versus Nash-Sutcliffe efficiency, and the coefficient a versus the exponent $\mathbf{b}$ when the topographic factor is calculated by using the equations 1 and 2 


$$
\begin{aligned}
& L S=\left(0.02222 J^{1.5}+0.03231 J+0.1004\right) * 0.2901 \triangle y^{0.4002} \text { for } J<5 \% \\
& L S=\left(0.02222 J^{1.5}+0.03231 J+0.1004\right) * 0.2105 \triangle y^{0.5004} \text { for } J>5 \%
\end{aligned}
$$

where $\mathrm{J}$ is the slope in $\%, \Delta y$ is the slope length. For description, readers are encouraged to watch it at https:/ /www.youtube.com/watch?v=w6w8jxbTJfo. For the case of the watersheds under our consideration, we take $\triangle \mathrm{y} / 22.1$ as the field slope length.

\section{Results}

From all graphs (see figures20,21,22,23,24,25 and 26), the best exponent (b) of the Modified Universal Soil Loss Equation is 1, which results in Nash-Sutcliffe efficiency of approximately 1 irrespective of the topographic factor and three watershed sizes (Hombole, Mojo and Gumera). As we can see from the graphs, for observed and simulated sediment, as the relationship between the coefficient $\mathbf{a}$ and the exponent $\mathbf{b}$ approaches to power or logarithmic function; the relationship between the exponentb and Nash-Sutcliffe efficiency approaches to a quadratic function. If we only consider one specific watershed, the best exponent $b$ and topographic factor that correspond to the largest Nash-Sutcliffe efficiency is read from a parabolic graph of the exponent $b$ versus Nash-Sutcliffe efficiency after calibration. If we consider two or more watersheds, the best exponent $\mathbf{b}$ and topographic factor that correspond to the largest but least NashSutcliffe efficiency as compared with other watersheds is read from parabolic graphs of the exponent $b$ versus Nash-Sutcliffe efficiency after calibration.

For Ethiopian condition, the best combination of the exponent $b$ and topographic factor which result in Nash-Sutcliffe efficiency greater than 0.8 are taken (see figures 20, $21,22,23,24,25$ and 26). In this case these four watersheds under our consideration are expected to represent any other watersheds of Ethiopia. Therefore, to regionalize the MUSLE under hydro-climatic condition of Ethiopia, the topographic factor is estimated by using the equations1 and 2 and McCool et al., (1987) as cited in[3]; the soil erodibility factor is estimated using Williams(1995) as cited in [106]; the soil cover and conservation practice factors are estimated from land use maps; the exponent $\mathbf{b}$ is estimated from $\mathbf{a}$ parabolic graph of the exponent $\mathbf{b}$ versus Nash-Sutcliffe efficiency, and the coefficient a is estimated from logarithmic or power graph of the coefficient $\mathbf{a}$ versus the exponent $\mathbf{b}$ after calibration.

\section{Discussion}

The exponent $\mathbf{b}$ of the MUSLE can be taken as a region-specific parameter for watersheds of Ethiopia where its value does not change from one to another watershed. The coefficient a of the MUSLE can be taken as a watershed specific constant where its value changes from one to another watershed. The coefficient a shows us soil erosion and sediment transport are site-specific problems and it reflects a unique feature of the watershed. These can be size of the watershed, temporal and spatial variations of soil properties, a density of land cover, types and extent of conservation practice, socio-economic activities (eg, Upper Awash River Basin), nature and extent of gully erosion (eg. Upper Awash River Basin), riverbank erosion, river bed erosion, rainfall distributions, a spatial resolution of data, pallow period, hydraulics of flow, etc. And also, runoff on-field slope area can form the shortest or longest route, which affects soil conservation practice factor, which also reflects the unique feature of the watershed.

The performance of the MUSLE was tested at watershed scale using observed flow data, and using its coefficient $\mathbf{a}$ and exponent $\mathbf{b}$ as calibration parameters. It shows good performance at all four watersheds of Ethiopia under our consideration; this result supports the literature review report by [5]) provided that its coefficient $\mathbf{a}$ and exponent $\mathbf{b}$ are changed for watersheds of Ethiopia. It also supports the conclusions of some authors as the MUSLE has been observed to give good results in various applications in some parts of tropical Africa (Ndomba, 2007) as cited in [8]; the MUSLE has been 
successfully demonstrated in sub-Saharan Africa [8]. In addition, it also supports the experimental plot result of sheet erosion at Enerta study site in Ethiopia, where the MUSLE was better to estimate soil loss from the cultivated field than the USLE [121].

\section{Conclusions}

In general, this paper mainly highlights the complexity associated with soil erosion and sediment transport, important features and advantages of the MUSLE as compared to the USLE/RUSLE for soil erosion modelling. Due to the complexity associated with soil erosion and sediment transport, better approaches and explanations are highly recommended to address soil erosion and sediment transport problems.

Author Contributions: This research article is part of $\mathrm{PhD}$ research by Manaye Getu Tsige; Andreas Malcherek, major supervisor; Yilma Seleshi, co-supervisor

Funding: This PhD research was funded by German Academic Exchange Service: EECBP Home Grown PhD Scholarship Programme, and equivalent funding will be from Universität der Bundeswehr: Scholarship and Support Program for Foreign Students and Doctoral Candidates (STIBET III) Matching Funds Scholarship

Data Availability Statement: Land use data sources are River Basin Authority of Ethiopia, Global land service, Google Earth Pro, Planet explorer, and Landsat images. Soil data sources are River Basin Authority of Ethiopia, Harmonized word soil data, field observation report from International Soil Reference and Information Centre. Climatic data from National Meteorology Agency of Ethiopia, flow and sediment data from River Basin Authority of Ethiopia, digital elevation models and Landsat image from US Geological Survey, other satellite image sources from Google Earth Pro and Planet explorer

Acknowledgments: We acknowledge Ms. Johanna Schmidt for language editing and LaTeX technical support.

Conflicts of Interest: The authors declare no conflict of interest.

\section{Appendix A}

Appendix A.1

Rainfall gauging stations in Upper Awash River Basin are Abebe Keranso (lat.8.978056 ${ }^{\circ} \mathrm{N}$ and $\log .38 .169167^{\circ} \mathrm{E}$ ), Addis Ababa (lat. 9.01891 ${ }^{\circ} \mathrm{N}$ and $\log .38 .7475^{\circ} \mathrm{E}$ ), Enselale (lat.8.937 and $\log .38 .44^{\circ} \mathrm{E}$ ), Ginchi (lat.9.01667 ${ }^{\circ} \mathrm{N}$ and $\left.\log .38 .1333^{\circ} \mathrm{E}\right)$, Guranda Meta (lat.8.912 ${ }^{\circ} \mathrm{N}$ and $38.593^{\circ} \mathrm{E}$ ), Hombole (lat. $8.368167^{\circ} \mathrm{N}$ and $\log .38 .78^{\circ} \mathrm{E}$ ), Kimoye (lat.9.013 ${ }^{\circ} \mathrm{N}$ and $\left.38.341^{\circ} \mathrm{E}\right), K_{\text {Koka }}$ Dam (lat.8.471 ${ }^{\circ} \mathrm{N}$ and $\left.\log .39 .157^{\circ} \mathrm{E}\right)$, Mojo (lat. $8.609^{\circ} \mathrm{N}$ and $\log .39 .114^{\circ} \mathrm{E}$ ), Sebeta (lat. $8.915^{\circ} \mathrm{N}$ and log. $38.629^{\circ} \mathrm{E}$ ), Sendafa (lat.9.152167 $\mathrm{N}$ and $\log .39 .0215^{\circ} \mathrm{E}$ ), Tefki (lat. $8.846^{\circ} \mathrm{N}$ and log. $38.494^{\circ} \mathrm{E}$ ), Teji (lat. $8.836^{\circ} \mathrm{N}$ and log. $38.375^{\circ} \mathrm{E}$ ), Tulu Bolo (lat. $8.658^{\circ} \mathrm{N}$ and $\log .38 .211^{\circ} \mathrm{E}$ ), Zequala (lat. $8.86667^{\circ} \mathrm{N}$ and $\log .38 .866667^{\circ} \mathrm{E}$ ), Addis Alem (lat. $9.042^{\circ} \mathrm{N}$ and $\log .38 .38333^{\circ} \mathrm{E}$ ), Alem Tena (lat.8.29 $\mathrm{N}$ and $\log .38 .90783^{\circ} \mathrm{E}$ ), Arbuchulele (lat. $8.47^{\circ} \mathrm{N}$ and $\log .38 .25133^{\circ} \mathrm{E}$ ), Asgori (lat. $8.79^{\circ} \mathrm{N}, \log .38 .3342^{\circ} \mathrm{E}$ ), Bantuliben (lat. $8.6185^{\circ} \mathrm{N}$ and $\log .38 .357^{\circ} \mathrm{E}$ ), Boneya (lat. $8.7845^{\circ} \mathrm{N}$ and $\log .38 .64167^{\circ} \mathrm{E}$ ), chefedonsa (lat. $8.97^{\circ} \mathrm{N}$ and log. $39.1232^{\circ} \mathrm{E}$ ), Debrezeit (lat. $8.733333^{\circ} \mathrm{N}$ and $\log$. $38.95^{\circ} \mathrm{E}$ ), Dilela (lat. $8.63583^{\circ} \mathrm{N}$ and $\log .38 .04083^{\circ} \mathrm{E}$ ), Dire Gidib (lat. $9.15783^{\circ} \mathrm{N}$ and $\log$. $38.943^{\circ} \mathrm{E}$ ), Ejersa Lele (lat. 8.2432 ${ }^{\circ} \mathrm{N}$ and $\log .38 .686^{\circ} \mathrm{E}$ ), Welenkomi (lat. $9.001833^{\circ} \mathrm{N}$ and 38.254667 $\mathrm{E})$.

Maximum and minimum temperature gauging stations in Upper Awash River basin Kimoye, Koka Dam, Mojo, Sebeta, Tefki, Tulu Bolo, Adis Alem, Alem Tena, Asgori, Boneya, Chefedonsa, Debrezeit and Dire Gidib.

Rainfall gauging stations in Gumera watershed are Amed Ber (lat. $11.9135^{\circ} \mathrm{N}$ and $\log .37 .8858^{\circ} \mathrm{E}$ ), Debre Tabor station (lat. $11.8666^{\circ} \mathrm{N}$ and $\log .37 .9954^{\circ} \mathrm{E}$ ), Gassay (lat. $\left.11.7971^{\circ} \mathrm{N} \log .38 .134497^{\circ} \mathrm{E}\right)$, Lewaye (lat. $11.72^{\circ} \mathrm{N}$ and $\left.\log .38 .07194^{\circ} \mathrm{E}\right)$, Licha $11.651^{\circ} \mathrm{N}$ 
and $37.885^{\circ} \mathrm{E}$, Mekaneyesus (lat. 11.6076 and log. 38.05422), Wanzaye (lat. $11.7862^{\circ} \mathrm{N}$ and $\left.\log .37 .67503^{\circ} \mathrm{E}\right)$.

Maximum and minimum temperature gauging stations in Gumera watershed are Amed Ber (lat. $11.9135^{\circ} \mathrm{N}$ and log. $37.8858^{\circ} \mathrm{E}$ ), Debre Tabor station (lat. $11.8666^{\circ} \mathrm{N}$ and $\log .37 .9954^{\circ} \mathrm{E}$ ), Gassay (lat. $\left.11.7971^{\circ} \mathrm{N} \log .38 .134497^{\circ} \mathrm{E}\right)$, Mekaneyesus (lat. 11.6076 and log. 38.05422 ), Wanzaye (lat. $11.7862^{\circ} \mathrm{N}$ and log. $37.67503^{\circ} \mathrm{E}$ ).

Rainfall gauging stations in Gilgel Gibe 1 watersheds are Ako (lat. $8.032117^{\circ} \mathrm{N}$ and long. $37.20255^{\circ} \mathrm{E}$ ), Assendabo (lat. $7.7605^{\circ} \mathrm{N}$ and $\log .37 .231117^{\circ} \mathrm{E}$ ), Chekorsa (lat. $7.616667^{\circ} \mathrm{N}$ and $\log .36 .733333^{\circ} \mathrm{E}$ ), Dedo (lat. $7.504233^{\circ} \mathrm{N}$ and log. $36.879717^{\circ} \mathrm{E}$ ), Busa (lat. $8.7725^{\circ} \mathrm{N}$ and $\log .38 .1382^{\circ} \mathrm{E}$ ), Dimtu (lat. $7.85^{\circ} \mathrm{N}$ and $\log .37 .2333^{\circ} \mathrm{E}$ ), Jiren Abajifar (lat. $7.700117^{\circ} \mathrm{N}$ and log. $36.706367^{\circ} \mathrm{E}$, Serbo (lat. $7.7^{\circ} \mathrm{N}$ and log. $36.966667^{\circ} \mathrm{E}$ ), Yebu (lat. $7.68333^{\circ} \mathrm{N}$ and $\left.\log .36 .816667^{\circ} \mathrm{E}\right)$.

Maximum and minimum temperature gauging stations in Gilgel Gibe 1 watershed are Ako (lat $8.032117^{\circ} \mathrm{N}$ and log. $37.20255^{\circ} \mathrm{E}$ ), Assendabo (lat. $7.7605^{\circ} \mathrm{N}$ and $\log .37 .231117^{\circ} \mathrm{E}$ ), Dedo (lat. $7.504233^{\circ} \mathrm{N}$ and log. $36.879717^{\circ} \mathrm{E}$ ), Busa (lat. $8.78^{\circ} \mathrm{N}$ and $\left.\log .38 .14^{\circ} \mathrm{E}\right)$, Yebu (lat. $7.68333^{\circ} \mathrm{N}$ and $\left.\log .36 .816667^{\circ} \mathrm{E}\right)$

\section{References}

1. Kumar P.S.; Praveen T.V.; Prasad M.A., Simulation of Sediment Yield Over Un-gauged Stations Using MUSLE and Fuzzy Model. Aquatic Procedia 2015 , 4, 1291-1298, doi:10.1016/J.AQPRO.2015.02.168

2. Kinnell P.I.A., A Review of the Science and Logic Associated with Approach Used in the Universal Soil Loss Equation Family of Models. Soil systems 2019 , doi:10.3390/soilsystems3040062

3. Pongsai S.; Vogt D.S.; Shrestha R.P.; Clemente R.S.; Apisit E., Calibration and validation of the Modified Universal Soil Loss Equation for estimating sediment yield on sloping plots: A case study in Khun Satan catchment of Northern Thailand. Canadian Journal of Soil Science $\mathbf{2 0 1 0}$, 90, 585-596, doi:10.4141/CJSS09076

4. Desmet P.J.J; Govers G., A GIS procedure for automatically calculating the USLE LS factor on topographically complex landscape units. Journal of Soil and Water Conservation 1996,51

5. Sadeghi S.H.R; Gholami L.; Darvishan A.K.; Saeidi P., A review of the application of the MUSLE model worldwide) A review of the application of the MUSLE model worldwide A review of the application of the MUSLE model worldwide A review of the application of the MUSLE model worldwide. Hydrological Sciences Journal 2014 , 59,365-375, doi:10.1080/02626667.2013.866239

6. Pandey A.; Chowdary V.M.; Mal B.C; Sediment yield modelling of an agricultural watershed using MUSLE, remote sensing and GIS. Paddy Water Environment 2009, 7 , 105-113, doi:10.1007/s10333-009-0149-y

7. Benavidez R.; Jackson B.; Maxwell D.; Norton K., A review of the (Revised) Universal Soil Loss Equation ((R)USLE): With a view to increasing its global applicability and improving soil loss estimates. Hydrology and Earth System Sciences 2018, 22,6059-6086, doi:10.5194/HESS-22-6059-2018

8. Adegede A.P.; Mbajiorgu C.C., Event-based sediment yield modelling using MUSLE in north-central Nigeria. Agricultural Engineering International: CIGR Journal 2019, 21,7-17, https: / / cigrjournal.org/index.php/Ejounral/article/view/5231

9. Sadeghi S.H.R; Mizuyama T., Applicability of the Modified Universal Soil Loss Equation for prediction of sediment yield in Khanmirza watershed, Iran.,Hydrological Sciences Journal 2007, 52, 1068-1075, doi:10.1623/hysj.52.5.1068

10. Gwapedza D.; Slaughter A.; Hughes D.; Mantel S., Regionalising MUSLE factors for application to a data-scarce catchment. Water Resources Assessment ans Seasonal Prediction, Proceedings of the International Association of Hydrological Sciences, 2018, Copernicus GmbH, 377, 19-24 , doi:10.5194/PIAHS-377-19-2018

11. Williams'J.R,SEDIMENT ROUTING FOR AGRICULTURAL WATERSHEDS'. WATER RESOURCES BULLETIN 1975, $11,965-974$.

12. Wischmeier W.H.; Smith D., Predicting rainfall erosion losses : a guide to conservation planning. USDA, 1978

13. Zhang H.; Wei J.; Yang Q.; Baartman J.E.M.; Gai L.; Yang X.; Li S.; Yu J.; Ritsema C.J.; Geissen V. , An improved method for calculating slope length and the LS parameters of the Revised Universal Soil Loss Equation for large watersheds. Geoderma 2017, 308 , 36-45, doi:10.1016/J.GEODERMA.2017.08.006

14. Arekhi S.; Shabani A.; Rostamizad G., Application of the modified universal soil loss equation (MUSLE) in prediction of sediment yield (Case study: Kengir Watershed, Iran. Arab J Geosci. 2012, 5, 1259-1267, doi:10.1007/s12517-010-0271-6

15. Ganasri B.P.; H. Ramesh H., Assessment of soil erosion by RUSLE model using remote sensing and GIS - A case study of Nethravathi Basin. Geoscience Frontiers 2016 , 7 , 953-961, doi:10.1016/J.GSF.2015.10.007

16. Kinnell P.I.A. , Event soil loss, runoff and the Universal Soil Loss Equation family of models: A review. Journal of Hydrology 2010, 385 , 384-397, doi:10.1016/J.JHYDROL.2010.01.024

17. Fagbohun B.J; Anifowose A.Y.B; Odeyemi C.; Aladejana O.O.; Aladeboyeje A.I., GIS-based estimation of soil erosion rates and identification of critical areas in Anambra sub-basin, Nigeria. Modeling Earth Systems and Environment 2016, 2 , doi: 10.1007 /s40808-016-0218-3

18. Mitasova H.; Hofierka J.; Zlocha M.; Iverson L.R., Modelling topographic potential for erosion and deposition using GIS . International Journal of Geographical Information Systems 1996 , 10 , 629-641, doi:10.1080/02693799608902101 
19. Renard K.G.; Yoder D.C; Lightle D.T; Dabney S.M., Handbook of Erosion Modelling: Universal Soil Loss Equation and Revised Universal Soil Loss Equation. Blackwell Publishing Ltd 2011.

20. Renard K.G.; Foster G.R.; Weesies G.A.; McCool D.K.; Yoder D.C. Predicting Soil Erosion by water: A Guide to conservation Planning with the Revised Universal Soil Loss Equation, USDA: USA, Agriculture Handbook, No 703, 404pp., 1997.

21. Baoyuan L.; Keli Z.; Yun X. , An Empirical Soil Loss Equation. Proceedings of 12th International Soil Conservation Organization Conference, Tsinghua University Press, Beijing, China, 2002, 21-25, https:/ / www.tucson.ars.ag.gov/isco/isco12/VolumeII/ AnEmpiricalSoilLossEquation.pdf

22. Tadesse A.; Dai W., Prediction of sedimentation in reservoirs by combining catchment based model and stream based model with limited data. International Journal of Sediment Research 2019, doi:10.1016/j.ijsrc.2018.08.001

23. Haregeweyn N.; Melesse B.; Tsunekawa A.; Tsubo M.; Meshesha D.; Balana B.B.,Reservoir sedimentation and its mitigating strategies: a case study of Angereb reservoir (NW Ethiopia). Journal of Soils and Sediments 2012, 12 , 291-305, doi:10.1007/s11368 $-011-0447-z$

24. Devi R.; Tesfahune E.; Legesse W.; Deboch B.; Beyene A., Assessment of siltation and nutrient enrichment of Gilgel Gibe dam, Southwest Ethiopia. Bioresource Technology 2008, 99 , 975-979, doi:10.1016/j.biortech.2007.03.013

25. Tully T.; Sullivan C.; Weil R.; Sanchez P., The State of Soil Degradation in Sub-Saharan Africa: Baselines, Trajectories, and Solutions. Sustainability 2015, 7 , 6523-6552, doi:10.3390/su7066523

26. Hurni K.; Zeleke G.; Kassie M.; Tegegne B.; Kassawmar T.; Teferi E.; Moges A.; Tadesse D.; Ahmed M.; Degu Y.; Kebebew Z.; Hodel E.; Amdihun A.; Mekuriaw A.; Debele B.; Deichert G.; Hurni H., Soil Degradation and Sustainable Land Management in the Rainfed Agricultural Areas of Ethiopia: An Assessment of the Economic Implications. Economics of Land Degradation (ELD) Ethiopia Case Study Report for the Economics of Land Degradation Initiative. 94 pp, 2015, accessed on 3 December 2021 from:www.eld-initiative.org

27. Tilahun S.A.; Ayana E.K; Guzman C.D.; Dagnew D.C.; Zegeye A.D.; Tebebu T.T.; Yitaferu B.; Tammo S. Steenhuis T.S. , Revisiting Storm Runoff Processes in the Upper Blue Nile Basin:The Debre Mawi Watershed. CATENA 2016 , 47-56, doi: 10.1016/j.catena.2016.03.029

28. Moges M.M.; Abay D.; Engidayehu H., Investigating reservoir sedimentation and its implications to watershed sediment yield: The case of two small dams in data-scarce upper Blue Nile Basin, Ethiopia . Lakes \& Reservoirs: Science, Policy E Management for Sustainable Use $2018,23,217-229$, doi:10.1111/LRE.12234

29. World Bank Group, The Cost of Land Degradation in Ethiopia: A Review of Past Studies. World Bank, Washington, D.C, 2007, http:/ / documents.worldbank.org/curated/en/2007/04/14059854/cost-land-degradation-ethiopia-review-past-studies

30. Tamene L.; Park S.J.; Dikau R.; Vlek P.L.G , Analysis of factors determining sediment yield variability in the highlands of northern Ethiopia. Geomorphology 2006 , 76 , 76 - 91, doi:10.1016/j.geomorph.2005.10.007

31. Haregeweyn N.; Poesen J.; Nyssen J.; Wit J.D.; Haile M.; Govers G.; Deckers S., Reservoirs in Tigray (Northern Ethiopia): characteristics and sediment deposition problems. land degradation $\mathcal{E}$ development $2006,17,211-230$, doi:10.1002/ldr.698

32. Amare S.; Langendoen E.; Keesstra S.; Ploeg M. van der; Gelagay H.; Lemma H.; Zee S. E. A. T. M. van der, Susceptibility to Gully Erosion: Applying Random Forest (RF) and Frequency Ratio (FR) Approaches to a Small Catchment in Ethiopia. Water 2021 , 13 , doi:10.3390/w13020216

33. Haregeweyn N.; Tsunekawa A.; Poesen J.; Tsubo M.; Meshesha D.T.; Fenta A.A.; Nyssen J.; Adgo E., Comprehensive assessment of soil erosion risk for better land use planning in river basins: Case study of the Upper Blue Nile River. Science of The Total Environment 2017, 574 , 95-108, doi:10.1016/j.scitotenv.2016.09.019

34. Tessema Y. M.; Jasi nska J.; Yadeta L. T.; Switoniak M.; Puchałka R.; Gebregeorgis E. G., Soil Loss Estimation for Conservation Planning in the Welmel Watershed of the Genale Dawa Basin, Ethiopia . Agronomy 2020, 10 , doi:10.3390/agronomy10060777

35. Wagari M.; Tamiru H., RUSLE Model Based Annual Soil Loss Quantification for Soil Erosion Protection:A Case of Fincha Catchment, Ethiopia. Air, Soil and Water Research 2021, doi:10.1177/117862212110462

36. Bekele B.; Gemi Y., Soil erosion risk and sediment yield assessment with universal soil loss equation and GIS: in Dijo watershed, Rift valley Basin of Ethiopia . Modeling Earth Systems and Environment 2021 , 7 , 273-291, doi:10.1007/s40808-020-01017-z

37. Gashaw T.; Tulu T.; Argaw M., Erosion risk assessment for prioritization of conservation measures in Geleda watershed, Blue Nile basin, Ethiopia. Environmental Systems Research 2017 , , doi:10.1186/s40068-016-0078-x

38. Frankl A.; Deckers J.; Moulaert L.; Damme A.V.; Haile M.; Poesen J.;Nyssen J., Integrated Solutions for Combating Gully Erosion in Areas Prone to Soil Piping: Innovations from the Drylands of Northern Ethiopia . land degradation E development 2014 , , doi:10.1002/ldr.2301

39. Balabathina V.N.; Raju R.P.; Mulualem W.; Tadele G., Estimation of soil loss using remote sensing and GIS-based universal soil loss equation in northern catchment of Lake Tana Sub-basin, Upper Blue Nile Basin, Northwest Ethiopia . Environmental Systems Research 2020 , 9, doi:10.1186/s40068-020-00203-3

40. Tadesse L.; K.V. Suryabhagavan K.V.; Sridhar G.; Legesse G., Land use and land cover changes and Soil erosion in Yezat Watershed, North Western Ethiopia. International Soil and Water Conservation Research 2017 , 5 , 85-94, doi:10.1016/j.iswcr.2017.05.004

41. Haile G.W.; Fetene M., Assessment of Soil Erosion Hazard in kilie Catchment, East Shoa, Ethiopia. land degradation E development $2012,23,293-306$, doi:10.1002/ldr.1082

42. Kidane M.; Bezie A.; Kesete N.; Tolessa T. ,The impact of land use and land cover (LULC) dynamics on soil erosion and sediment yield in Ethiopia. Heliyon 2019, 5 , e02981, doi:10.1016/j.heliyon.2019.e02981 
43. Degife A.; Worku H.; Gizaw S., Environmental implications of soil erosion and sediment yield in Lake Hawassa watershed, south-central Ethiopia. Environmental Systems Research 2021 , 10 , doi:10.1186/s40068-021-00232-6

44. Wolka K.; Tadesse H.; Garedew E.; Yimer F., Soil erosion risk assessment in the Chaleleka wetland watershed, Central Rift Valley of Ethiopia. Environmental Systems Research 2015, 4 , doi:10.1186/s40068-015-0030-5

45. Haregeweyn N.; Tsunekawa A.; Nyssen j.; Poesen J.; Tsubo M.; Meshesha D.T.; Sch'utt B.; Adgo E.; Tegegne F., Soil erosion and conservation in Ethiopia: A review. Progress in Physical Geography 2015, , 750-774, doi:10.1177/0309133315598725

46. Yesuph A.Y.; Amare Bantider Dagnew A.B., Soil erosion mapping and severity analysis based on RUSLE model and local perception in the Beshillo Catchment of the Blue Nile Basin, Ethiopia. Environmental Systems Research 2019, 8, doi:10.1186/s40068 -019-0145-1

47. Aga A. O.; Chane B.; Melesse A. M., Soil Erosion Modelling and Risk Assessment in Data Scarce Rift Valley Lake Regions, Ethiopia. Water 2018 , 10 , doi:10.3390/w10111684

48. Gelagay H.S.; Minale A.S. ,Soil loss estimation using GIS and Remote sensing techniques: A case of Koga watershed, Northwestern Ethiopia. International Soil and Water Conservation Research 2016 , 4,126-136, doi:10.1016/j.iswcr.2016.01.002

49. Lemma H.; Frankl A.; Dessie M.; Poesen J.; Adgo E.; Nyssen J., Consolidated sediment budget of Lake Tana, Ethiopia (2012-2016). Geomorphology 2020 , 371 , doi:10.1016/j.geomorph.2020.107434

50. Krop ačeK J.; Schillaci C.; Salvini R.; M'arKer M., Assessment of Gully Erosion in the Upper Awash, Central Ethiopian Highlands Based on a Comparison of Archived Aerial Photographs and Very High Resolution Satellite Images. Geogr. Fis. Dinam. Quat. 2016, doi:10.4461/GFDQ2016.39.15

51. AN, L. S.; Liao K. H.; Zhou B. H.; Pan W.; Chen Q., Global Sensitivity Analysis of the Parameters of the Modified Universal Soil Loss Equation. Applied Ecology and Environmental Research 2016, 14,505-514, doi:10.15666/aeer/1404\$_\$505514

52. Odongo V.O; Onyando J.O.; Mutua B.M.; van Oel P.R.; Becht R., Sensitivity analysis and calibration of the Modified Universal Soil Loss Equation (MUSLE) for the upper Malewa Catchment, Kenya. International Journal of Sediment Research 2013 , 28,368-383, doi:10.1016/S1001-6279(13)60047-5

53. Fenta A.A.; Tsunekawa A.; Haregeweyn N.; Tsubo M.; Yasuda H.; Kawai T.; Ebabu K.; Berihun M.L.; Belay A.S.; Dagnenet S., Agroecology-based soil erosion assessment for better conservation planning in Ethiopian river basins. Environmental Research 2021,195 , doi:10.1016/j.envres.2021.110786

54. Kuttah D.; Sato K., Review on the effect of gypsum content on soil behavior. Transportation Geotechnics 2015, 4,28-37 doi: 10.1016/j.trgeo.2015.06.003

55. Blanco-Canqui H.; Benjamin J.G.,Impacts of Soil Organic Carbon on Soil Physical Behavior. Advances in Agricultural Systems Modeling 2013, 3 , doi:10.2134/advagricsystmodel3.c2

56. EKWUE E.I. , Organic-Matter Effects on Soil Strength Properties. Soil \& Tillage Research 1990 , , $289-297$.

57. Jeloudar F.T.; Sepanlou M.G.; Emadi S.M., Impact of land use change on soil erodibility. Global J. Environ. Sci. Manage 2018, 4, 59-70, doi:10.22034/gjesm.2018.04.01.006

58. Rimmeri D.L; Greenland D.J., Effects of Calcium Carbonate on the Swelling Behaviour of a Soil Clay. Journal of Soil Science 1976.

59. Matsumoto S.; Ogata S.; Shimada H.; Sasaoka T.; Hamanaka A.; Kusuma G. J., Effects of pH-Induced Changes in Soil Physical Characteristics on the Development of Soil Water Erosion. Geosciences 2018, 8, 2076-3263, doi:10.3390/geosciences8040134

60. Wei L.; Zhang B.; Wang M., Effects of antecedent soil moisture on runoff and soil erosion in alley cropping systems .Agricultural Water Management 2007, 94,54-62, doi:10.1016/j.agwat.2007.08.007

61. Jien S.-H.; Wang C.-S.,Effects of biochar on soil properties and erosion potential in a highly weathered soil. CATENA 2013, 110,225-233, doi:10.1016/j.catena.2013.06.021

62. Cai P.; Sun X.; Wu Y.; Gao C.; Mortimer M.; Holden P.A.; Redmile-Gordon M; Huang Q., Soil biofilms: microbial interactions, challenges, and advanced techniques for ex-situ characterization. 2019 , Soil Ecol. Lett ,85-93 , doi:10.1007/s42832-019-0017-7

63. Neave M.; Rayburg S., Salinity and erosion: a preliminary investigation of soil erosion on a salinized hillslope. Sediment Dynamics and the Hydromorphology of Fluvial Systems Proceedings of a symposium held in Dundee, UK, July 2006, IAHS Publ.306, 2006.

64. Razavian, S.M. and Wenby, R.B. and Fisher, T.C. and Meiselman, H.J.,Determination of Particle Sedimentation Rate by Ultrasonic Interferometry: Role of Particle Size, Density and Volume Fraction. Biorheology 1997, 34 ,349-362 , doi:10.3233/BIR-1997-344-507

65. Rousseva S.; Torri D.; Pagliai M., Effect of rain on the macroporosity at the soil surface. European Journal of Soil Science 2002 , 53 ,83-94, doi:10.1046/j.1365-2389.2002.00426.x

66. Dlapa P.; Hrin lk D.; Hrabovsk y A.; Šimkovic I.; Žarnovi čan H.; Sekucia F.; Koll ar J., The Impact of Land-Use on the Hierarchical Pore Size Distribution and Water Retention Properties in Loamy Soils. 12 2020, Water, doi:10.3390/w12020339

67. Lee C.-H.; Low Y.M.; Chiew Y.-M. , Multi-dimensional rheology-based twophase model for sediment transport and applications to sheet flow and pipeline scour. Phys. Fluids 28, 053305 2016, doi:10.1063/1.4948987

68. Jepsen R.; Roberts J.; Lick W., Effects of Bulk Density on Sediment Erosion Rates. Water, Air and Soil Pollution 1997, 21-31.

69. Jing H.; Chen G.; Wang W.; Li G., Effects of concentration-dependent settling velocity on nonequilibrium transport of suspended sediment. Environmental Earth Sciences 2018 , 77, doi:10.1007/s12665-018-7731-9

70. Torri D.; Poesen J.; Borselli L.; Bryan R.;Rossi M.,Spatial variation of bed roughness in eroding rills and gullies. CATENA 2012 , $90,76-86$,doi:10.1016/j.catena.2011.10.004 
71. Sanford L.P., Modeling a dynamically varying mixed sediment bed with erosion, deposition, bioturbation, consolidation, and armoring. Computers E Geosciences 2008 , 34 , 1263-1283, doi:10.1016/j.cageo.2008.02.011

72. Gabet E.J.; Reichman O.J.; Seabloom E.W., The Effects of Bioturbation on Soil Processes and Sediment Transport. Annu. Rev. Earth Planet. Sci 2003 , 31 , 249-273, doi:10.1146/annurev.earth.31.100901.141314

73. Fang K.; Kou D.; Wang G.;Chen L.; Ding J.; Li F.; Yang G.; Qin S.; Liu L.; Zhang Q.; Yang Y.Decreased Soil Cation Exchange Capacity Across Northern China's Grasslands Over the Last Three Decades, Journal of Geophysical Research: Biogeosciences 2017 , 122 , 3088-3097, doi:10.1002/2017JG003968

74. KABA£A C.; £ABAZ B., Relationships between soil $\mathrm{pH}$ and base saturation - conclusions for Polish and international soil classifications. SOIL SCIENCE ANNUAL $2018,69,206$-214, doi:10.2478/ssa-2018-0021

75. Belay A.; Claassens A.S.; Wehner F.C., Effect of direct nitrogen and potassium and residual phosphorus fertilizers on soil chemical properties, microbial components and maize yield under long-term crop rotation. Biol Fertil Soils 2002, 35, 420-427, doi:10.1007/s00374-002-0489-x

76. Boekel P.;Peerlkamp P.L., Soil consistency as a factor determining the soil structure of clay soils. Wageningen journal of life sciences 1956, 4, doi:10.18174/njas.v4i1.17792

77. Julie A. Hope and David M. Paterson and Simon F. Thrush, The role of microphytobenthos in soft-sediment ecological networks and their contribution to the delivery of multiple ecosystem services.Journal of Ecology 2020 , 108, 815-830, doi:10.1111/1365-2 745.13322

78. Vaidya G.S.; MC Rillig M.C.;Wallander H., The role of glomalin in soil erosion. Scientific World 2011 , 9 , 82-85, doi:10.3126/sw.v9 i9.5524

79. Cyco n\} M.; Mrozik A.; Piotrowska-Seget, Z., Antibiotics in the Soil Environment—Degradation and Their Impact on Microbial Activity and Diversity. Frontiers in Microbiology 2019, 10, doi:10.3389/fmicb.2019.00338

80. Powlson D.S.; Hirsch P.R.; Brookes P.C. , The role of soil microorganisms in soil organic matter conservation in the tropics. Nutrient Cycling in Agroecosystems 2001, 61, 41-51.

81. Sofo A.; Mininni A. N.; Ricciuti P., Soil Macrofauna: A key Factor for Increasing Soil Fertility and Promoting Sustainable Soil Use in Fruit Orchard Agrosystems. Agronomy 2020 , 10 , doi:10.3390/agronomy10040456

82. Jain R.K.; Kothyari U.C., Cohesion influences on erosion and bed load transport. Water Resources Research 2009 , 45 , doi: 10.1029/2008WR007044

83. Brunori F.; Penzo M.C.; Torri D., Soil shear strength: Its measurement and soil detachability.CATENA 1989 , 16, 59-71, doi:10.1016/0341-8162(89)90004-0

84. Tadese M.; Kumar L.; Koech R.; Kogo B.K., Mapping of land-use/land-cover changes and its dynamics in Awash River Basin using remote sensing and GIS.Remote Sensing Applications: Society and Environment 2020 , 19 , doi:10.1016/j.rsase.2020.100352

85. Shawul A.A.; Chakma S., Spatiotemporal detection of land use/land cover change in the large basin using integrated approaches of remote sensing and GIS in the Upper Awash basin, Ethiopia. Environmental Earth Sciences 2019 , 78 , doi:10.1007/s12665-019-8154-y

86. Alemayehu A. Shawul and Sumedha Chakma and Assefa M. Melesse, The response of water balance components to land cover change based on hydrologic modeling and partial least squares regression (PLSR) analysis in the Upper Awash Basin. Journal of Hydrology: Regional Studies 2019 , 26, doi:10.1016/j.ejrh.2019.100640

87. Bogale A. , Review, impact of land use/cover change on soil erosion in the Lake Tana Basin, Upper Blue Nile, Ethiopia . Applied Water Science 2020 , 10 , doi:10.1007/s13201-020-01325-w

88. Asselman N.E.M , Fitting and interpretation of sediment rating curves.Journal of Hydrology 2000 , 234, 228-248, doi:10.1016/S002 2-1694(00)00253-5

89. Heng S.; Suetsugi T., Comparison of regionalization approaches in parameterizing sediment rating curve in ungauged catchments for subsequent instantaneous sediment yield prediction. Journal of Hydrology 2014 , 512 , 240-253, doi:10.1016/j.jhydrol.2014.03.003

90. Jansson M.B. , Estimating a sediment rating curve of the Reventazón river at Palomo using logged mean loads within discharge classes. Journal of Hydrology 1996,183 , 227-241, doi:10.1016/0022-1694(95)02988-5

91. Hapsari D.; Onishi T.; Imaizumi F.; Noda K.; Senge M., The Use of Sediment Rating Curve under its Limitations to Estimate the Suspended Load. Reviews in Agricultural Science 2019 , 7, 88-101, doi:10.7831/ras.7.0_88

92. Sykes A.O., An Introduction to Regression Analysis. Coase-Sandor Institute for Law \& Economics Working Paper No. 20, 1993, https://chicagounbound.uchicago.edu/law_and_economics

93. David J. Finney, A note on the history of regression. Journal of Applied Statistics 1996, 23 ,555-557, doi:10.1080/02664769624099

94. Efthimiou N., The role of sediment rating curve development methodology on river load modeling.Environmental Monitoring and Assessment 2019, 191 , doi:10.1007/s10661-018-7167-4

95. Doomen A.M.C.; Wijma E.; Zwolsman J.J.K.; Middelkoop H., Predicting suspended sediment concentrations in the Meuse River using a supply-based rating curve. Hydrological Processes 2008 , 22 , 1846-1856, doi:10.1002/hyp.6767

96. Arthur J. Horowitz, An evaluation of sediment rating curves for estimating suspended sediment concentrations for subsequent flux calculations. Hydrological Processes $2003,17,3387$-3409, doi:10.1002/hyp.1299

97. Talebia A.; Bahrami A.; Mardian M.; Mahjoobi J., Determination of optimized sediment rating equation and its relationship with physical characteristics of watershed in semiarid regions: A case study of Pol-Doab waters . Desert 2015 , 20 , 135-144, doi:10.22059/JDESERT.2015.56477 
98. Balamurugan G., The Use of Suspended Sediment Rating Curves In Malaysia: Some Preliminary Considerations . Pertanika 1989 , $12,367-376$.

99. Chen L.; Qian X.; Shi Y., Critical Area Identification of Potential Soil Loss in a Typical Watershed of the Three Gorges Reservoir Region. Water Resour Manage. 2011 , 25 , 3445-3463, doi:10.1007/s11269-011-9864-4

100. David W.P., Soil and Water Conservation Planning: Policy Issues and Recommendations. Journal of Philippine Development 1988, $X V, 47-84$, doi:

101. Wischmeier W.H.; Mannering J.V., Relation of Soil Properties to its Erodibility. SOIL SCI. SOC. AMER. PROC 1969 , 33.

102. Morgan R.P.C.; Soil Erosion and Conservation, Blackwell Science Ltd, 2005, ISBN 1-4051-1781-8.

103. Schmidt S.; Tresch S.; Meusburger K., Modification of the RUSLE slope length and steepness factor (LS-factor) based on rainfall experiments at steep alpine grasslands. MethodsX 2019, 6, 219-229, doi:10.1016/j.mex.2019.01.004

104. Cole; Cooley; Dyke; Favis-Mortlock; Foster; Hanson; Jones; Jones O.R.; Kiniry; Laflen; Lyles; Nicks; Onstad; Richardson; Robertson; Sharpley; Smith; Smith F.R; Spanel; Springer; Steiner; williams, EPIC—Erosion/Productivity Impact Calculator, United States Department of Agriculture, Agricultural Research Service, Technical Bulletin Number 1768, 1990.

105. Kruk E. ,Use of Chosen Methods for Determination of the USLE Soil Erodibility Factor on the Example of Loess Slope . Journal of Ecological Engineering 2021 , 22 , 151-161, doi:10.12911/22998993/128861

106. Wawer R.; Nowocien E.; Podolski B., Real and Calculated K ${ }_{U S L E}$ Erodibility Factor for Selected Polish Soils . Polish Journal of Environmental Studies $2005,14,655-658$.

107. Wang B.; Zheng F.; Guan Y., Improved USLE-K factor prediction: A case study on water erosion areas in China. International Soil and Water Conservation Research 2016 , 4, 168-176, doi:10.1016/j.iswcr.2016.08.003

108. Panagos P.; Meusburger K.; Ballabio C.; Borrelli P.; Alewell C. ,Soil erodibility in Europe: A high-resolution dataset based on LUCAS. Science of The Total Environment 2014, 479-480, 189-200, doi:10.1016/j.scitotenv.2014.02.010

109. Liu B.; Xie Y.; Li Z.; Liang Y.; Zhang W.; Fu S.; Yin S.; Wei X.; Zhang K.; Wang Z.; Liu Y.; Zhao Y.; Guo Q.,The assessment of soil loss by water erosion in China . International Soil and Water Conservation Research 2020 , 8, 430-439, doi:10.1016/j.iswcr.2020.07.002

110. Moore I.D.; Wilson J.P , Length-slope factors for the Revised Universal Soil Loss Equation: Simplified method of estimation . Journal of Soil and Water Conservation $1992,47,423-428$.

111. Wang; Liu , Effects of land use changes on soil erosion in a fast developing area.int. J. Environ. Sci. Technol. 2014, 11, 1549-1562, doi:10.1007/s13762-013-0341-x

112. Knijff van der J.M, Jones R.J.A \& Montanarella L., Soil Erosion Risk Assessment in Europe. European Soil Bureau, 2000.

113. Jang C.; Shin Y.; Kum D.;Kim R.; Yang J.E.; Kim S.C.; Hwang S.I.; Lim K.J. Yoon J.-K.; Park Y.S.;Jung Y., Assessment of soil loss in South Korea based on land-cover type.Stochastic Environmental Research and Risk Assessment 2015, 29, 2127-2141, doi:10.1007/s00477-015-1027-3

114. Luo Y.; Yang S.; Liu X.; Liu C.; Zhang Y.; Zhou Q.; Zhou X.; Dong G., Suitability of revision to MUSLE for estimating sediment yield in the Loess Plateau of China.Stochastic Environmental Research and Risk Assessment 2016 , 30 , 379_-394, doi:10.1007/s00477-0 15-1131-4

115. Msadala V. C.; Basson G. R., Revised regional sediment yield prediction methodology for ungauged catchments in South Africa. Journal of the South African Institution of Civil Engineering 2017 , 59 , 28-36 , doi:10.17159/2309-8775/2017/v59n2a4

116. Noack M.; Gerbersdorf S.U.; Hillebrand G.; Wieprecht S., Combining Field and Laboratory Measurements to Determine the Erosion Risk of Cohesive Sediments Best. Water 2015,7 , 5061-5077, doi:10.3390/w7095061

117. Li J.; Wang W.; Guo M.; Kang H.; Wang Z.; Huang J.; Sun B.; Wang K.; Zhang G.; Bai Y., Effects of soil texture and gravel content on the infiltration and soil loss of spoil heaps under simulated rainfall. Journal of Soils and Sediments 2020, 20 , doi: 10.1007/s11368-020-02729-6

118. Sadeghi S.H.; Mizuyama T.; Vangah B.G., Conformity of MUSLE Estimates and Erosion Plot Data for Storm-Wise Sediment Yield Estimation. Terr. Atmos. Ocean. Sci. $2007,18,117-128$.

119. Kinnell P.I.A., Why the universal soil loss equation and the revised version of it do not predict event erosion well. HYDROLOGICAL PROCESSES 2005, 19 , 851-854, 10.1002/hyp.5816

120. Ndomba, Modelling of Sedimentation Upstream of Nyumba Ya Mungu Reservoir in Pangani River Basin. Nile Basin Water Science and Engineering Journal 2010, 3, 25-38.

121. Muche H.; Temesgen M.; Yimer F., Soil loss prediction using USLE and MUSLE under conservation tillage integrated with 'fanya juus' in Choke Mountain, Ethiopia. International Journal of Agricultural Sciences 2013, 3,46-52 https: / /internationalscholarsjournals. org / print.php?article=soil-loss-predictionusing

122. Soil Conservation Service, Geologic Investigation for Watershed Planning, USDA, Technical Release No. 17 Geology, 1966, https: / / directives.sc.egov.usda.gov/OpenNonWebContent.aspx?content=18602.wba

123. Williams J.R; Berndt H.D., Sediment Yield Prediction Based on Watershed Hydrology, ASAE 1977, 1100-1104 doi:10.13031/2013. 35710 